\title{
Modeling U.S. Energy Use Changes with Global Climate Change
}

September 2006

\author{
Prepared by \\ Stanton W. Hadley \\ David J. Erickson III \\ Jose Luis Hernandez
}




\title{
DOCUMENT AVAILABILITY
}

Reports produced after January 1, 1996, are generally available free via the U.S. Department of Energy (DOE) Information Bridge:

Web site: http://www.osti.gov/bridge

Reports produced before January 1, 1996, may be purchased by members of the public from the following source:

\author{
National Technical Information Service \\ 5285 Port Royal Road \\ Springfield, VA 22161 \\ Telephone: 703-605-6000 (1-800-553-6847) \\ TDD: 703-487-4639 \\ Fax: 703-605-6900 \\ E-mail: info@ntis.fedworld.gov \\ Web site: http://www.ntis.gov/support/ordernowabout.htm
}

Reports are available to DOE employees, DOE contractors, Energy Technology Data Exchange (ETDE) representatives, and International Nuclear Information System (INIS) representatives from the following source:

Office of Scientific and Technical Information

P.O. Box 62

Oak Ridge, TN 37831

Telephone: 865-576-8401

Fax: 865-576-5728

E-mail: reports@adonis.osti.gov

Web site: http://www.osti.gov/contact.html

\begin{abstract}
This report was prepared as an account of work sponsored by an agency of the United States Government. Neither the United States government nor any agency thereof, nor any of their employees, makes any warranty, express or implied, or assumes any legal liability or responsibility for the accuracy, completeness, or usefulness of any information, apparatus, product, or process disclosed, or represents that its use would not infringe privately owned rights. Reference herein to any specific commercial product, process, or service by trade name, trademark, manufacturer, or otherwise, does not necessarily constitute or imply its endorsement, recommendation, or favoring by the United States Government or any agency thereof. The views and opinions of authors expressed herein do not necessarily state or reflect those of the United States Government or any agency thereof.
\end{abstract}




\section{Modeling U.S. Energy Use Changes with Global Climate Change}

Stanton W. Hadley

David J. Erickson III

Jose Luis Hernandez

September 2006

OAK RIDGE NATIONAL LABORATORY

Oak Ridge, Tennessee 37831

managed by

UT-BATTELLE, LLC

for the

U.S. DEPARTMENT OF ENERGY

under contract No. DE-AC05-00OR22725 


\section{CONTENTS}

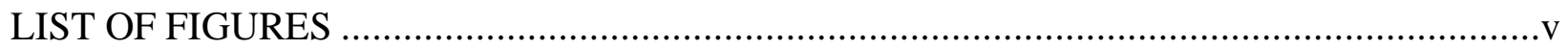

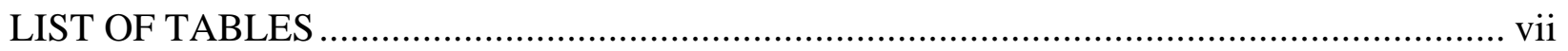

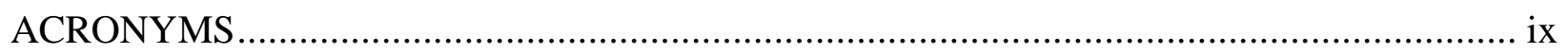

ACKNOWLEDGEMENTS ......................................................................................

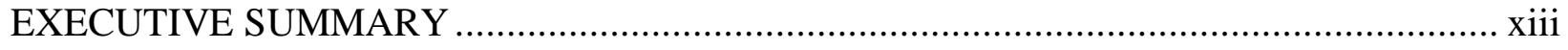

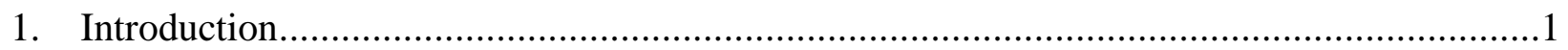

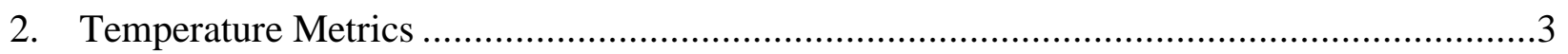

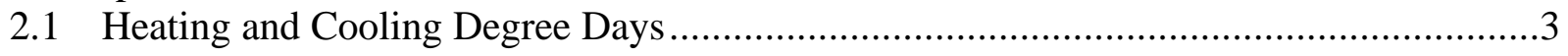

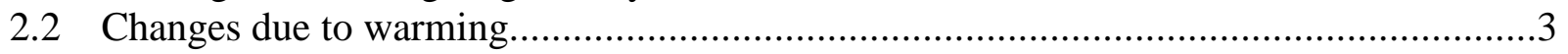

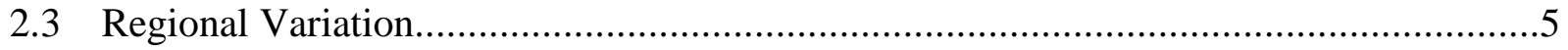

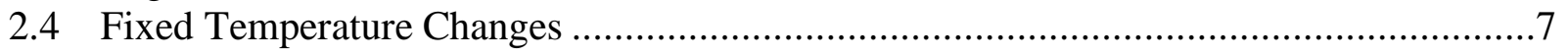

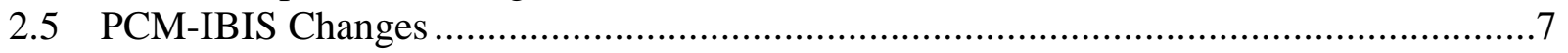

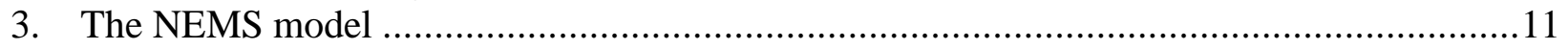

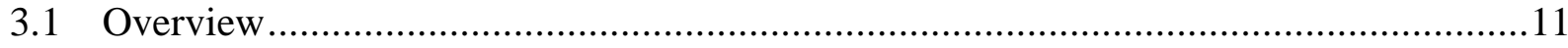

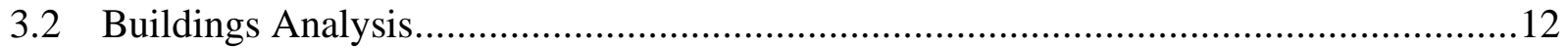

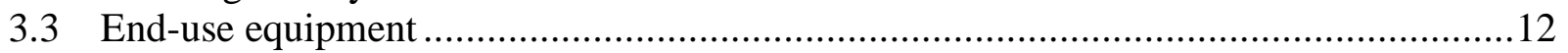

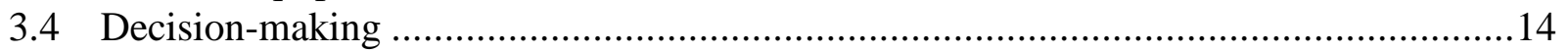

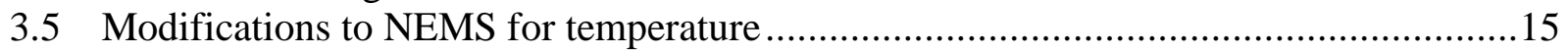

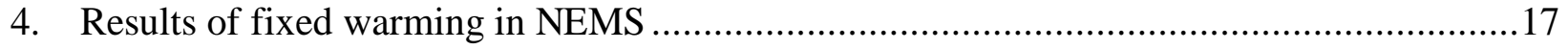

5. Results Using PCM-IBIS with Low Temperature Response ........................................21

5.1 Regional Energy Use Change ................................................................21

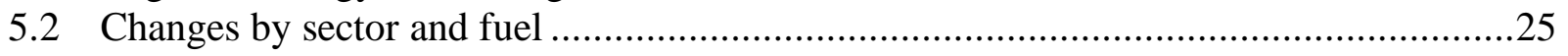

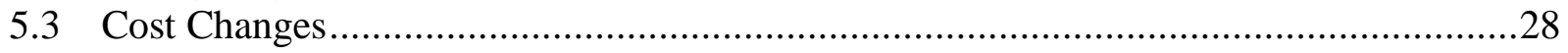

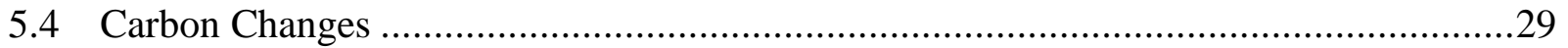

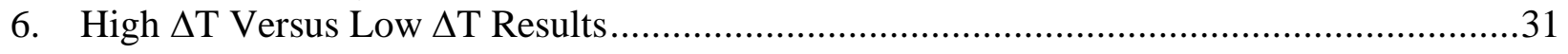

6.1 Temperature Differences ......................................................................... 31

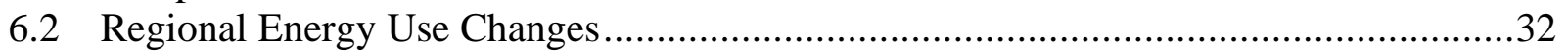

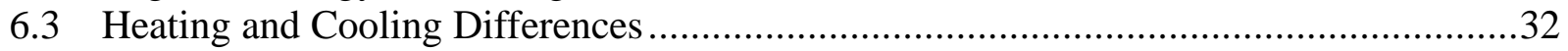

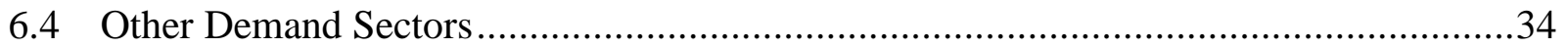

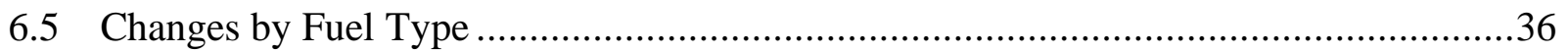

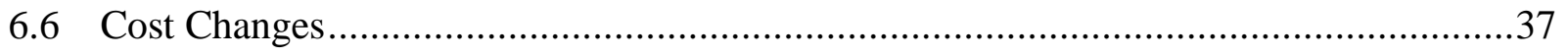

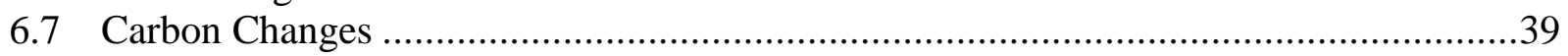

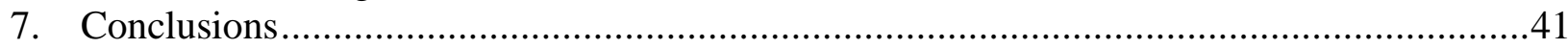

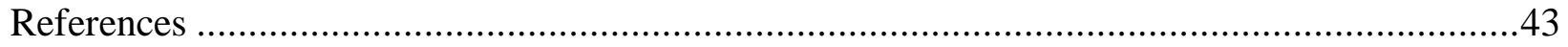





\section{LIST OF FIGURES}

Figure 1. Change in CDD as function of initial CDD and HDD ........................................

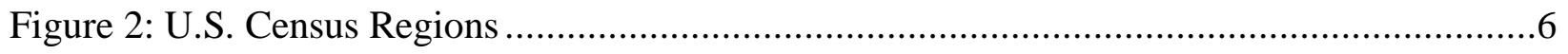

Figure 3. NCDC data and PCM-IBIS Adjustments .........................................................8

Figure 4. Annual average temperature from NCDC (pre-2002) and adjusted from the PCM-IBIS low- $\Delta$ T scenario (post 2002). Dashed lines show the NCDC 1971-2000 averages...............9

Figure 5: National Energy Modeling System ......................................................... 12

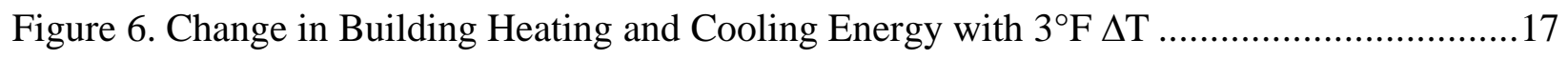

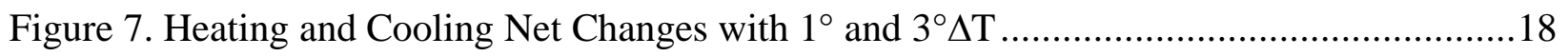

Figure 8. Primary Energy Use Differences between the Reference and $3^{\circ} \Delta \mathrm{T}$ Scenarios............19

Figure 9: Change in energy cost with increase in average temperature................................20

Figure 10. Change in carbon emissions with increase in average temperature.........................20

Figure 11. Cumulative change in end-use heating and cooling energy between by 2025 with varying degree-days vs. constant degree-days.

Figure 12. Cumulative change in primary heating and cooling energy between by 2025 with

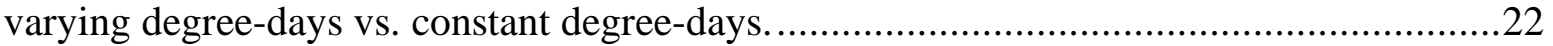

Figure 13. National change in heating and cooling end-use and primary energy amounts .........23

Figure 14. Change in net primary energy use for heating and cooling in the northern and

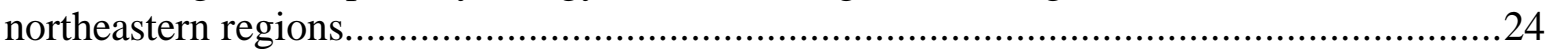

Figure 15. Change in net primary energy use for heating and cooling in the southern regions....24

Figure 16. Change in net primary energy use for heating and cooling in the western regions and Nationally.

Figure 17. Change in national primary energy use for heating, cooling, other sectors, and total.26

Figure 18. Change in national energy supply by fuel type. .27

Figure 19. National energy price differences between the base case and with varying temperatures .28

Figure 20. National cost changes for heat and cooling end-use and for all energy use....... .29

Figure 21. Carbon emission changes in the Low $\Delta \mathrm{T}$ Scenarios .30

Figure 22. Average temperature increase for 2003-2025 in the High- $\Delta \mathrm{T}$ versus the Low- $\Delta \mathrm{T}$ scenarios by region

Figure 23. Cumulative change (2003-2025) in end-use and primary heating and cooling energy between the High- $\Delta \mathrm{T}$ scenario and the Reference scenario. 32

Figure 24. Primary energy change from Reference for heating and cooling in each scenario......33

Figure 25 . Change in net primary energy use as $\%$ of total heating and cooling energy for North 
Central regions (East and West) and South regions (West, East, and Atlantic)

Figure 26. Change in national primary energy use for heating, cooling, other sectors, and total for the Low- $\Delta \mathrm{T}$ scenario

Figure 27. Change in national primary energy use for heating, cooling, other sectors, and total for the High- $\Delta \mathrm{T}$ scenario.

Figure 28. Change in national energy supply by fuel type the High- $\Delta \mathrm{T}$ scenario......................36

Figure 29. Average fuel price changes between the High- $\Delta \mathrm{T}$ and Reference scenarios. .............38

Figure 30. Cumulative heating and cooling cost difference from Reference scenario for each

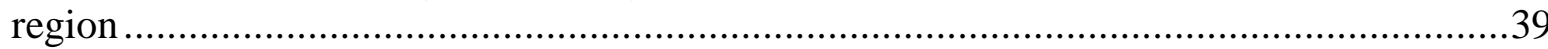

Figure 31. Carbon emission changes from Reference scenario.........................................40

Figure 32. Carbon emission changes from reference scenario for each variation of temperature

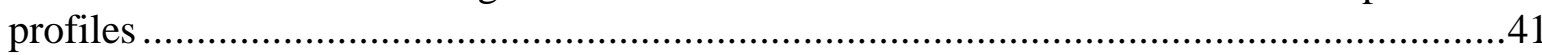




\section{LIST OF TABLES}

Table 1: Long-term Mean Cooling Degree Days (calculated from NCDC data).......................6

Table 2: Long-term Mean Heating Degree Days (calculated from NCDC data) .......................6

Table 3: Change in Cooling Degree Days from a one-degree rise in temperature........................7

Table 4: Change in Heating Degree Days from a one-degree rise in temperature .......................7

Table 5: Services and Equipment in the NEMS Residential Sector Demand Module ................14

Table 6: Building types and end-use services in NEMS Commercial Demand Module.............14

Table 7. Residential Energy Use in 2025 for the Reference and $3^{\circ} \Delta \mathrm{T}$ Scenarios (Quads) ..........18

Table 8. Reference scenario heating and cooling primary energy use 2003-2025 (Quads).........21

Table 9. Cumulative changes in electricity capacity by technology by 2025 (GW) ................27

Table 10. Change in heating and cooling cost for each region (million 2001\$) ......................29

Table 11. Reference scenario degree-days (1971-2000 averages) and average change in 20032025 from Reference scenario for Low- $\Delta \mathrm{T}$ and High- $\Delta \mathrm{T}$ scenarios..............................31

Table 12. Total primary energy increases (decreases) for heating, cooling, and net energy between the two varying temperature scenarios and the Reference scenario. (Quads).........33

Table 13. Cumulative energy change by sector (Quads) ................................................35

Table 14. Cumulative energy change by fuel (Quads) ......................................................

Table 15. Cumulative changes in electricity capacity by technology by 2025 (GW) ...............37

Table 16. Change in heating and cooling cost for each region (\$Billion) ..............................38

Energy Use and Climate Change vii 



\section{ACRONYMS}

$\begin{array}{ll}\text { AEO2003 } & \text { Annual Energy Outlook 2003 } \\ \text { CDD } & \text { Cooling degree-days } \\ \text { DD-NEMS } & \text { Degree-Day National Energy Modeling System } \\ \text { EIA } & \text { Energy Information Administration } \\ \text { GW } & \text { Gigawatt } \\ \text { HDD } & \text { Heating degree-days } \\ \text { kWh } & \text { Kilowatt-hours } \\ \text { mmBtu } & \text { Million British Thermal Units } \\ \text { NCDC } & \text { National Climatic Data Center } \\ \text { NEMS } & \text { National Energy Modeling System } \\ \text { PCM-IBIS } & \text { Parallel Climate Model-Integrated Biosphere Simulator } \\ \text { Quads } & \text { Quadrillion (10 }{ }^{15} \text { ) British Thermal Units } \\ \text { SEDS } & \text { State Energy Data System }\end{array}$





\section{ACKNOWLEDGEMENTS}

This research was supported by the U.S. Department of Energy, Office of Science and the Laboratory Directed Research and Development fund at Oak Ridge National Laboratory. The authors would like to thank Thomas Wilbanks of ORNL for his valuable support on this project, both the initial funding through Laboratory Directed R\&D for the NEMS model and ongoing encouragement. We would especially like to thank T. J. Blasing of ORNL for his invaluable comments, insights, and rewriting that helped make the paper more clear and readable. 



\section{EXECUTIVE SUMMARY}

Using a general circulation model of Earth climate (PCM-IBIS) to drive an energy use model (DD-NEMS), we calculated the energy use changes for each year from 2003-2025 for the nine U.S. Census regions. We used five scenarios: 1) a reference with no change in temperatures from the $1970-2003$ average, 2) a gradual $1^{\circ} \mathrm{F}$ rise in temperature by 2025,3 ) a gradual $3^{\circ} \mathrm{F}$ rise by 2025 , 4) a climate simulation with low temperature response to $\mathrm{CO}_{2}$ doubling in the atmosphere, and 5) a climate simulation with a more extreme response.

In general, large but opposite effects in different regions of the U.S. tended to cancel each other so that national changes were relatively small. For example, the low- $\Delta \mathrm{T}$ scenario had a cumulative reduction through 2025 in energy of 2.1 Quads but an increase in cost of $\$ 14.8$ billion. The northern states had reductions in cost over the entire period, but most other regions had increases in costs because increases in cooling costs outweighed reductions in heating and other energy uses. Higher temperature sensitivity (the high- $\Delta \mathrm{T}$ scenario) resulted in increased warming, especially in the winter months. Because heating needs decreased, total energy requirements declined by a cumulative 4.2 Quads, twice that of the low- $\Delta \mathrm{T}$ scenario. However, total cost still increased $\$ 6.1$ billion. Regional analysis shows a much larger impact in the southern regions of the U.S., while some northern regions have energy and cost savings over the whole span of time studied.

Relative carbon emissions rose for all scenarios studied as coal-based electricity for cooling needs grew, as compared to the reference scenario (Figure ES-1). The scenario with a gradual $1^{\circ} \mathrm{F}$ rise by 2025 had the lowest impact, but the others had similar amounts of change. In all cases, there was an initial decline as heating reductions outpaced cooling increases, but with additional temperature increases, the cooling-related increases overwhelmed the other impacts and carbon emissions rose. While the amounts in any year are small, the trend indicates that there would be a continued build-up with increasing warmth.

Figure ES-1. Carbon emission changes from reference scenario for each variation of temperature profiles

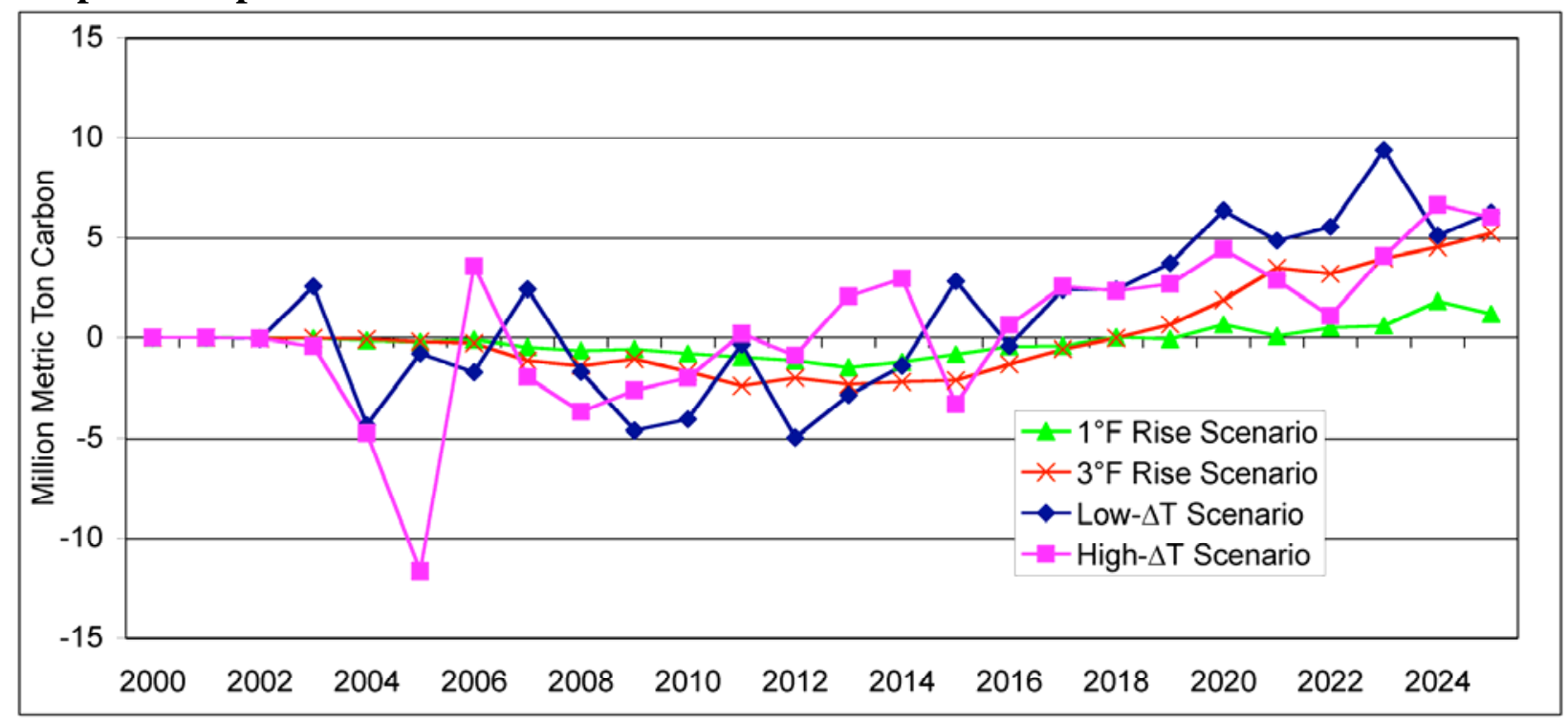




\section{Introduction}

The increase in atmospheric $\mathrm{CO}_{2}$ that has been observed continues and will result in changes in atmospheric temperatures. The National Assessment Synthesis Team identified in Climate Change Impacts on the United States (NAST 2000) many processes that will be affected by climate change. One little-studied aspect of warming will be a climate-related change in the amount of heating and cooling needed by buildings in the U.S. These changes will increase or decrease the cost to consumers, depending on the types of energy used. The changes will affect the various regions of the country differently, with some possibly seeing a higher cost and others a lower cost. Overall carbon emissions could also change as a consequence, leading to a slight feedback effect on climate change. (Throughout this paper we use "carbon emitted as $\mathrm{CO}_{2}$ " rather than $\mathrm{CO}_{2}$ because the results are useful to carbon-cycle modelers, who track the carbon atoms instead of $\mathrm{CO}_{2}$ molecules. To convert to $\mathrm{CO}_{2}$, multiply by 44/12.)

To calculate the change in energy demand, carbon emissions, and associated financial impacts of alterations in heating and cooling, three elements are needed: regional data on temperatures past and future, conversion of temperature changes into heating and cooling requirements, and a model to translate the requirements into energy use and economic consequences. For historic temperatures and heating/cooling needs, we used data from the National Climatic Data Center (NCDC) on heating and cooling degree-days for various regions of the country. For this analysis, three methods for establishing future temperatures were used. The first analysis used a simple ramp-up in temperatures over time, to $1^{\circ}$ and $3^{\circ} \mathrm{F}$ for all regions. The second and third methods for future temperatures used results from the Parallel Climate Model-Integrated Biosphere Simulator (PCM-IBIS) climate simulator. One scenario used a set of temperature changes from the climate simulator assuming low sensitivity of the atmosphere to greenhouse gas concentrations were used. The other scenario used a set of temperatures from the simulator assuming high sensitivities.

Separately, we conducted a probabilistic analysis of the change in degree-days with an increase in temperature so that monthly temperature changes could be converted to heating/cooling degree-days. Lastly, to convert these degree-day changes into regional energy and cost changes, we used a modified version of the National Energy Modeling System (NEMS) from the Department of Energy's Energy Information Administration (EIA). The modification allowed the model to accept annual temperature-related information through 2025, instead of just through 2003 as their reference model does; we refer to our revised version as DD-NEMS.

Rosenthal, Gruenspecht, and Moran conducted a similar but smaller scale analysis in 1995 (Rosenthal et al. 1995). They presumed a $1{ }^{\circ} \mathrm{C}$ increase in global temperature in 2010. They used the results from five global circulation models to estimate the consequent temperature rise on five climate regions in the US along with national building survey data to estimate the cost impacts for that year. Their analysis showed a slight reduction in total U.S. energy requirements and costs as temperatures increased. However, their study did not involve running the NEMS model but rather used offline calculations from a single reference NEMS run. Consequently, it did not capture the details and temporal changes in climate, energy demands, and consequent supplies that we could with the global circulation model and DD-NEMS. Model results reported here project forward to year 2025 and capture the results of dominating changes in energy 
demand for space cooling as more people live in warm climates and rely more on air conditioning.

This paper presents the results through 2025 from the three scenarios and the reference assumptions (no temperature increase) from the Annual Energy Outlook 2003 (EIA 2003a). While limited to only the U.S. and for a relatively short study period, these analyses provide insight into the national and regional impact on energy use and costs from changing temperatures over time. Chapter 2 of the paper describes the methodology used to convert temperature changes in heating and cooling requirements changes. Chapter 3 describes the NEMS model and how heating and cooling needs are calculated. Chapter 4 describes the results with a steady temperature increase that is the same for all regions. Chapter 5 describes the results from the low $\Delta \mathrm{T}$ sensitivity, and Chapter 6 compares the results from the high $\Delta \mathrm{T}$ sensitivity to the low $\Delta \mathrm{T}$ sensitivity cases. The results give details at the regional level on energy use, economic cost, and carbon emission changes. We conclude the paper in Chapter 7. 


\section{Temperature Metrics}

\subsection{Heating and Cooling Degree Days}

The main metrics of the effect of outside temperature on heating or cooling loads are heating degree-days (HDD) and cooling degree-days (CDD). These measure the difference between the average ambient temperature for the day and a given reference temperature. Monthly average values of several climatic variables for each of 354 regions ("climatic divisions") within the United States are available from 1931 forward (NCDC 2003a and 2003b). Averages are derived from data at several locations within each climatic division. For heating and cooling degree days, values are weighted by the population distribution within each region to better represent heating and cooling loads. The NCDC uses $65^{\circ} \mathrm{F}$ as the reference temperature (and was also used in this study.)

Heating and cooling degree-days can only be positive, so that when the daily average temperature $\left(\mathrm{T}_{\text {avg }}\right)$ is below $65^{\circ} \mathrm{F}$ heating degree days occur and when $\mathrm{T}_{\text {avg }}$ is above $65^{\circ}$ then CDD occur.

$\mathrm{HDD}=\sum\left(65-\mathrm{T}_{\text {avg }}\right)$, for days with $\mathrm{T}_{\mathrm{avg}}<=65^{\circ}$

$\mathrm{CDD}=\sum\left(\mathrm{T}_{\text {avg }}-65\right)$, for days with $\mathrm{T}_{\text {avg }}>65^{\circ}$

Degree-days may be summed over weeks, months, or seasons to represent both the heating and cooling needed. Increases in daily temperatures will raise the monthly number of CDD, lower the number of HDD, or a combination of both because days with $T_{\text {avg }}$ above and below $65^{\circ} \mathrm{F}$ can occur within a given month. In summer, increases will mostly affect the CDD while winter changes will affect the HDD. However, in months with both HDD and CDD, any increase in temperature will generally have a proportional impact on the two factors as a function of the proportion of CDD to HDD. We used a random-walk simulation to determine a relationship between the relevant factors.

The Rosenthal paper reports that a different equilibrium temperature may more accurately reflect the heating and cooling loads on a building (Rosenthal et al. 1995). If a building has significant internal heat generating equipment within, then cooling may still be required despite an ambient temperature less than $65^{\circ}$. Equilibrium points as low as $50^{\circ}$ may be more accurate for some types of commercial facilities, while residential buildings may be $60^{\circ}$. Other alternatives may be justifiable, such as different equilibrium points for heating versus cooling, if people are willing to accept some band of ambient temperatures where neither heating nor cooling are required. Because both the NEMS model and NCDC data are predicated on the $65^{\circ}$ standard, we did not attempt to use alternatives. However, these factors may be of interest in further studies.

\subsection{Changes due to warming}

Simulated warming in a region will increase CDD and decrease HDD. A one degree increase in temperature for a month should result in a decrease in HDD plus an increase in CDD that total to the number of days in the month. The split between the two will depend on the average temperature for the month or the relative proportion of heating versus cooling degree-days 
normally for that month. This is most important since space cooling and heating are provided by different technologies, equipment, and fuel.

Warming in mid-winter at high latitudes will most often simply lower the number of heating degree days, while in the summer the major effect will be an increase in the cooling degree days. However, when a given month has both heating and cooling degree-days it becomes more difficult to estimate how much the warming will lower the HDD or raise the CDD.

To explore this we set up a "month" of thirty days where we started the first day at a random average temperature between $40^{\circ} \mathrm{F}$ and $90^{\circ} \mathrm{F}$. We then set the average temperature for each following day at the value of the previous day plus or minus a random amount, with limits on the change either $\pm 5^{\circ} \mathrm{F}$ or $10^{\circ} \mathrm{F}$ per day. This "random walk" simulated various possible monthly temperature patterns from which we could calculate the monthly CDD and HDD. For each day in the simulated month we also added a warming factor of $1^{\circ}, 3^{\circ}$, or $5^{\circ}$ and calculated the CDD and HDD for each of these months with warming. We calculated degree-day changes for 8,130 of these simulated months.

Given the original CDD and HDD for any given month and some warming, what function can define the new values of CDD and HDD? We chose the independent value to be the ratio of CDD to CDD plus HDD and the dependent value to be the ratio of the increase in CDD to the total warming impact:

$\mathrm{x}=\mathrm{CDD} /(\mathrm{CDD}+\mathrm{HDD})$, and, for a 30-day month,

$\mathrm{y}=\Delta \mathrm{CDD} /(\Delta \mathrm{CDD}-\Delta \mathrm{HDD})=\Delta \mathrm{CDD} /(30 *$ warming degrees $)$

As mentioned earlier, in cold months the number of CDD would be zero and the warming impact would be totally in reducing the HDD; $x$ and y would equal zero. In hot months the HDD would be zero and all of the warming would serve to raise the CDD; $x$ and $y$ would equal one. When the temperatures average $65^{\circ} \mathrm{F}$ (and CDD equals HDD) then CDD and HDD should be affected equally; $x$ and y should equal 0.5 . A sample plot of over 600 months with the initial temperature at $65^{\circ} \mathrm{F}$, random walk factors of $\pm 5^{\circ} \mathrm{F}$, and $+1^{\circ} \mathrm{F}$ of warming is shown in Figure 1. Each solid blue diamond represents a simulated month with its associated CDD and HDD values. Cold months are on the left (few or no CDD) and hot months are on the right (few or no HDD). 
Figure 1. Change in CDD as function of initial CDD and HDD

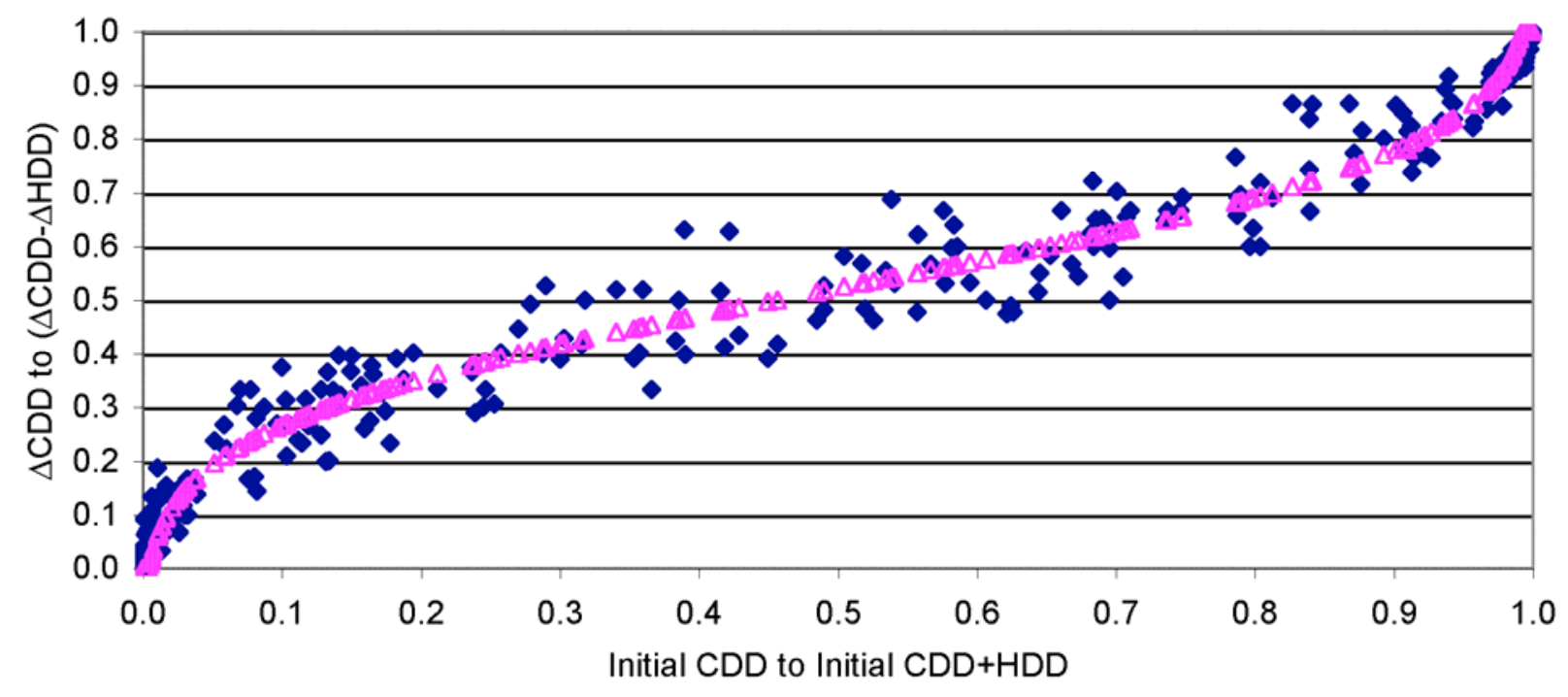

As can be seen in the figure, the best fit is not a straight-line correspondence between the initial values and the same values with heating added. Instead, we used an inverse cumulative normal distribution to fit to the points. Also, the y-values may read high because as temperatures are added to the days of the month, $\mathrm{T}_{\text {avg }}$ values slightly below $65^{\circ}$ may increase to over $65^{\circ}$ so that CDD will increase and HDD decrease. The equation used is:

$y=\operatorname{NORMINV}(x$, mean, stdev $)$

where $\mathrm{x}=\mathrm{CDD} /(\mathrm{CDD}+\mathrm{HDD})$

mean $=0.5+0.02245^{*}$ warming degrees

and stdev $=0.1923$

The results of the equation are also shown in Figure 1 as open triangles. The numeric values for the mean and standard deviation were determined by solving to minimize the sum of the squares of the difference between the calculated CDD after warming and the actual CDD after warming.

\subsection{Regional Variation}

As can be expected, different parts of the country face much different heating and cooling needs. NCDC provides monthly population-weighted (1990 census) degree-day info for the nine census regions shown below (Figure 2). The reports that NCDC provide contain the values for each month, as well as variations of these values from the long-term means. From these latter values, the long-term means can be calculated, as shown in Table 1 and Table 2. 
Figure 2: U.S. Census Regions

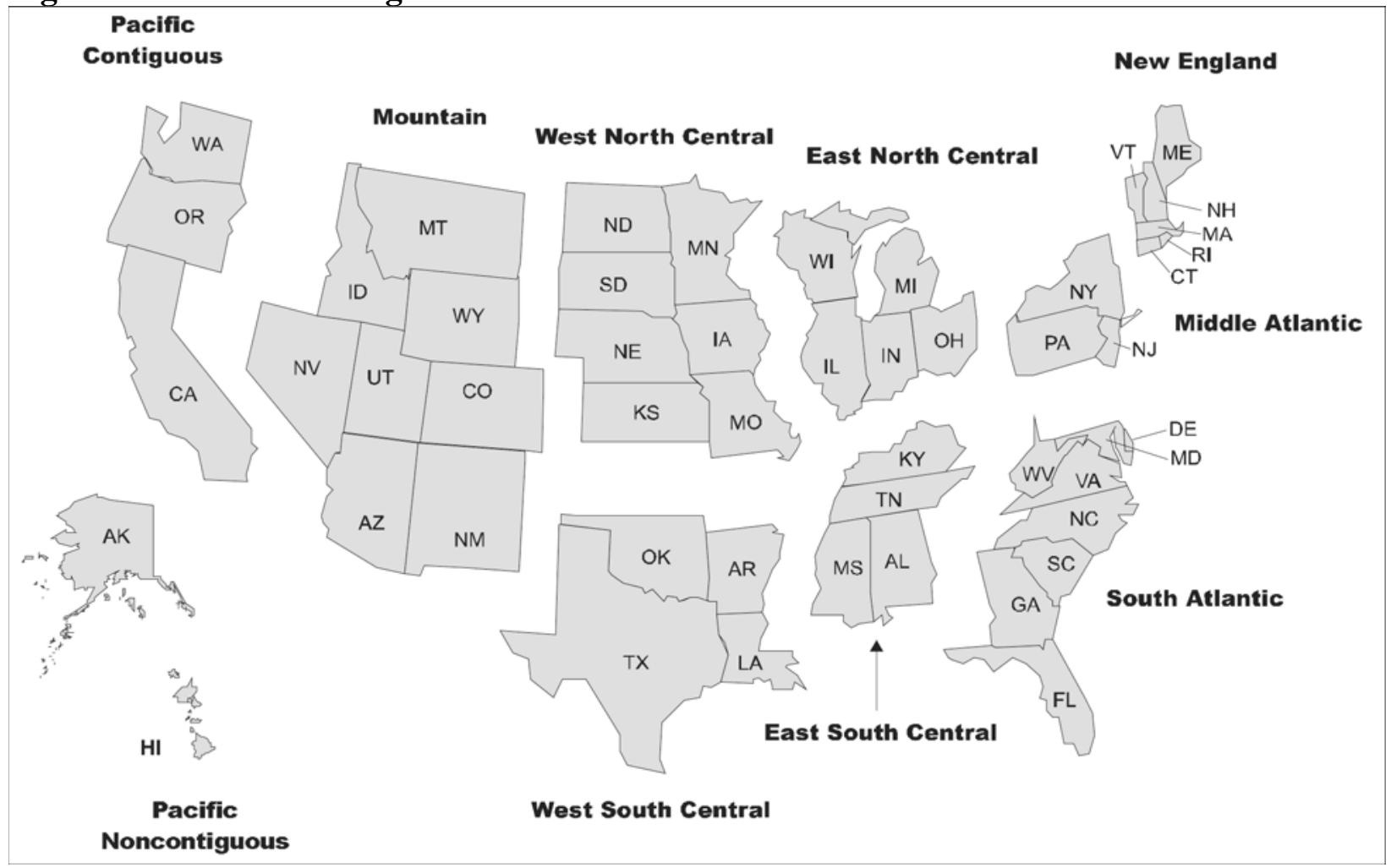

Table 1: Long-term Mean Cooling Degree Days (calculated from NCDC data)

\begin{tabular}{|l|rrrrrrrrrrrrr|}
\hline Region & JAN & FEB & MAR & APR & MAY & JUN & JUL & AUG & SEP & OCT & NOV & DEC & SUM \\
\hline New England & 0 & 0 & 0 & 0 & 5 & 64 & 179 & 148 & 25 & 1 & 0 & 0 & 421 \\
Mid Atlantic & 0 & 0 & 0 & 0 & 24 & 121 & 247 & 210 & 68 & 5 & 0 & 0 & 675 \\
E. N. Central & 0 & 0 & 0 & 1 & 53 & 152 & 249 & 201 & 69 & 11 & 0 & 0 & 735 \\
W. N. Central & 0 & 0 & 2 & 9 & 72 & 200 & 325 & 263 & 94 & 17 & 0 & 0 & 982 \\
S. Atlantic & 30 & 27 & 48 & 71 & 177 & 314 & 413 & 391 & 259 & 119 & 49 & 30 & 1927 \\
E. S. Central & 7 & 4 & 19 & 34 & 142 & 298 & 403 & 375 & 218 & 57 & 6 & 4 & 1565 \\
W. S. Central & 12 & 11 & 47 & 109 & 253 & 427 & 544 & 528 & 349 & 137 & 33 & 10 & 2461 \\
Mountain & 0 & 2 & 9 & 31 & 86 & 214 & 337 & 287 & 153 & 51 & 4 & 1 & 1173 \\
Pacific & 1 & 2 & 3 & 12 & 31 & 97 & 191 & 193 & 122 & 38 & 4 & 0 & 694 \\
\hline
\end{tabular}

Table 2: Long-term Mean Heating Degree Days (calculated from NCDC data)

\begin{tabular}{|l|ccccccccccccc|}
\hline \multicolumn{1}{|c|}{ Region } & JAN & FEB & MAR & APR & MAY & JUN & JUL & AUG & SEP & OCT & NOV & DEC & SUM \\
\hline New England & 1262 & 1085 & 919 & 581 & 274 & 60 & 7 & 24 & 140 & 439 & 720 & 1110 & 6621 \\
Mid Atlantic & 1171 & 1001 & 821 & 483 & 201 & 31 & 4 & 13 & 89 & 368 & 646 & 1012 & 5840 \\
E. N. Central & 1314 & 1094 & 868 & 484 & 217 & 42 & 5 & 20 & 102 & 402 & 730 & 1144 & 6422 \\
W. N. Central & 1398 & 1107 & 865 & 438 & 190 & 41 & 9 & 23 & 123 & 396 & 798 & 1247 & 6635 \\
S. Atlantic & 670 & 538 & 379 & 169 & 51 & 4 & 0 & 1 & 19 & 158 & 335 & 571 & 2895 \\
E. S. Central & 843 & 657 & 455 & 188 & 62 & 3 & 0 & 0 & 25 & 204 & 432 & 719 & 3588 \\
W. S. Central & 620 & 447 & 277 & 75 & 10 & 0 & 0 & 0 & 5 & 78 & 272 & 523 & 2306 \\
Mountain & 991 & 766 & 676 & 433 & 230 & 79 & 13 & 26 & 134 & 357 & 665 & 950 & 5320 \\
Pacific & 574 & 438 & 432 & 311 & 184 & 78 & 22 & 21 & 61 & 175 & 384 & 565 & 3245 \\
\hline
\end{tabular}




\subsection{Fixed Temperature Changes}

The equation for converting temperature increases of $1^{\circ}$ and $3^{\circ} \mathrm{F}$ was applied to each month for each region using the values from Table 1 and Table 2. For example, Table 3 and Table 4 show the increase and decrease in the two factors for each region with one degree of warming. Summing these calculations over the year gives the annual CDD and HDD for each region given a one-degree increase. Similar calculations can be done for any other increase or decrease. The CDD and HDD for each year and region were changed linearly from the 2003 values in 2003 to the full $\left(1^{\circ} \mathrm{F}\right.$ or $\left.3^{\circ} \mathrm{F}\right)$ values in 2025 .

Table 3: Change in Cooling Degree Days from a one-degree rise in temperature

\begin{tabular}{|l|rrrrrrrrrrrrr|}
\hline \multicolumn{1}{|c|}{ Region } & JAN & FEB & MAR & APR & MAY & JUN & JUL & AUG & SEP & OCT & NOV & DEC & SUM \\
\hline New England & 0 & 0 & 0 & 0 & 4 & 16 & 27 & 23 & 10 & 0 & 0 & 0 & 80 \\
Mid Atlantic & 0 & 0 & 0 & 0 & 9 & 20 & 29 & 26 & 15 & 3 & 0 & 0 & 102 \\
E. N. Central & 0 & 0 & 0 & 0 & 11 & 20 & 28 & 24 & 14 & 5 & 0 & 0 & 102 \\
W. N. Central & 0 & 0 & 0 & 4 & 13 & 21 & 28 & 25 & 15 & 6 & 0 & 0 & 112 \\
S. Atlantic & 6 & 6 & 9 & 13 & 21 & 29 & 31 & 31 & 24 & 15 & 9 & 6 & 200 \\
E. S. Central & 2 & 1 & 6 & 10 & 19 & 29 & 31 & 31 & 23 & 12 & 3 & 1 & 168 \\
W. S. Central & 4 & 4 & 10 & 17 & 27 & 30 & 31 & 31 & 28 & 18 & 9 & 4 & 213 \\
Mountain & 0 & 0 & 3 & 7 & 13 & 19 & 27 & 24 & 16 & 9 & 1 & 0 & 119 \\
Pacific & 0 & 1 & 2 & 5 & 10 & 16 & 24 & 24 & 18 & 11 & 2 & 0 & 113 \\
\hline
\end{tabular}

Table 4: Change in Heating Degree Days from a one-degree rise in temperature

\begin{tabular}{|l|rrrrrrrrrrrrr|}
\hline \multicolumn{1}{|c|}{ Region } & JAN & FEB & MAR & APR & MAY & JUN & JUL & AUG & SEP & OCT & NOV & DEC & SUM \\
\hline New England & -31 & -28 & -31 & -30 & -27 & -14 & -4 & -8 & -20 & -31 & -30 & -31 & -285 \\
Mid Atlantic & -31 & -28 & -31 & -30 & -22 & -10 & -2 & -5 & -15 & -28 & -30 & -31 & -263 \\
E. N. Central & -31 & -28 & -31 & -30 & -20 & -10 & -3 & -7 & -16 & -26 & -30 & -31 & -263 \\
W. N. Central & -31 & -28 & -31 & -26 & -18 & -9 & -3 & -6 & -15 & -25 & -30 & -31 & -253 \\
S. Atlantic & -25 & -22 & -22 & -17 & -10 & -1 & 0 & 0 & -6 & -16 & -21 & -25 & -165 \\
E. S. Central & -29 & -27 & -25 & -20 & -12 & -1 & 0 & 0 & -7 & -19 & -27 & -30 & -197 \\
W. S. Central & -27 & -24 & -21 & -13 & -4 & 0 & 0 & 0 & -2 & -13 & -21 & -27 & -152 \\
Mountain & -31 & -28 & -28 & -23 & -18 & -11 & -4 & -7 & -14 & -22 & -29 & -31 & -246 \\
Pacific & -31 & -27 & -29 & -25 & -21 & -14 & -7 & -7 & -12 & -20 & -28 & -31 & -252 \\
\hline
\end{tabular}

\subsection{PCM-IBIS Changes}

Climate simulation provides spatially and temporally varying temperature estimates. The PCMIBIS model (Parallel Climate Model-Integrated BIosphere Simulator) [a version of the Parallel Climate Model (Barnett et al., 2002; Meehl et al.; 2000; Washington et al., 2000)] provides surface temperature data on $2.5^{\circ} \times 2.5^{\circ}$ latitude-longitude increments across the globe for every 15 minutes from 1900 to 2100 (Thompson et al., 2004). The data for the U.S. were aggregated both geographically and temporally into the monthly average temperatures for each of the nine census regions for 1971 to 2025 . For this analysis two PCM-IBIS computer run were used: a "Low- $\Delta \mathrm{T}$ " scenario with a low temperature response to $\mathrm{CO}_{2}$ doubling $\left(2.1^{\circ} \mathrm{F}\right)$, and a "High- $\Delta \mathrm{T}$ " scenario with higher response $\left(6.1^{\circ} \mathrm{F}\right)$. Different models simulate different temperatures for a given time and place, so further analysis should be done using an ensemble of cases to establish more robust results. 
Because the two scenarios have different responses to $\mathrm{CO}_{2}$, their regional temperature profiles, even historic, are different. These need to be calibrated against the actual values from NCDC, both because the NCDC values are properly weighted for population and so that results are comparable between the two scenarios. To do this we calculated the 1971-2000 monthly average temperatures for each scenario and the NCDC data. We then raised the monthly temperatures for 2003-2025 in the two scenarios by the difference in these averages to reflect the population weighting and reflect actual historical values. Figure 3 provides an example for one of the nine regions; each region would have its own adjustment based on the NCDC and PCM-IBIS data.

\section{Figure 3. NCDC data and PCM-IBIS Adjustments}

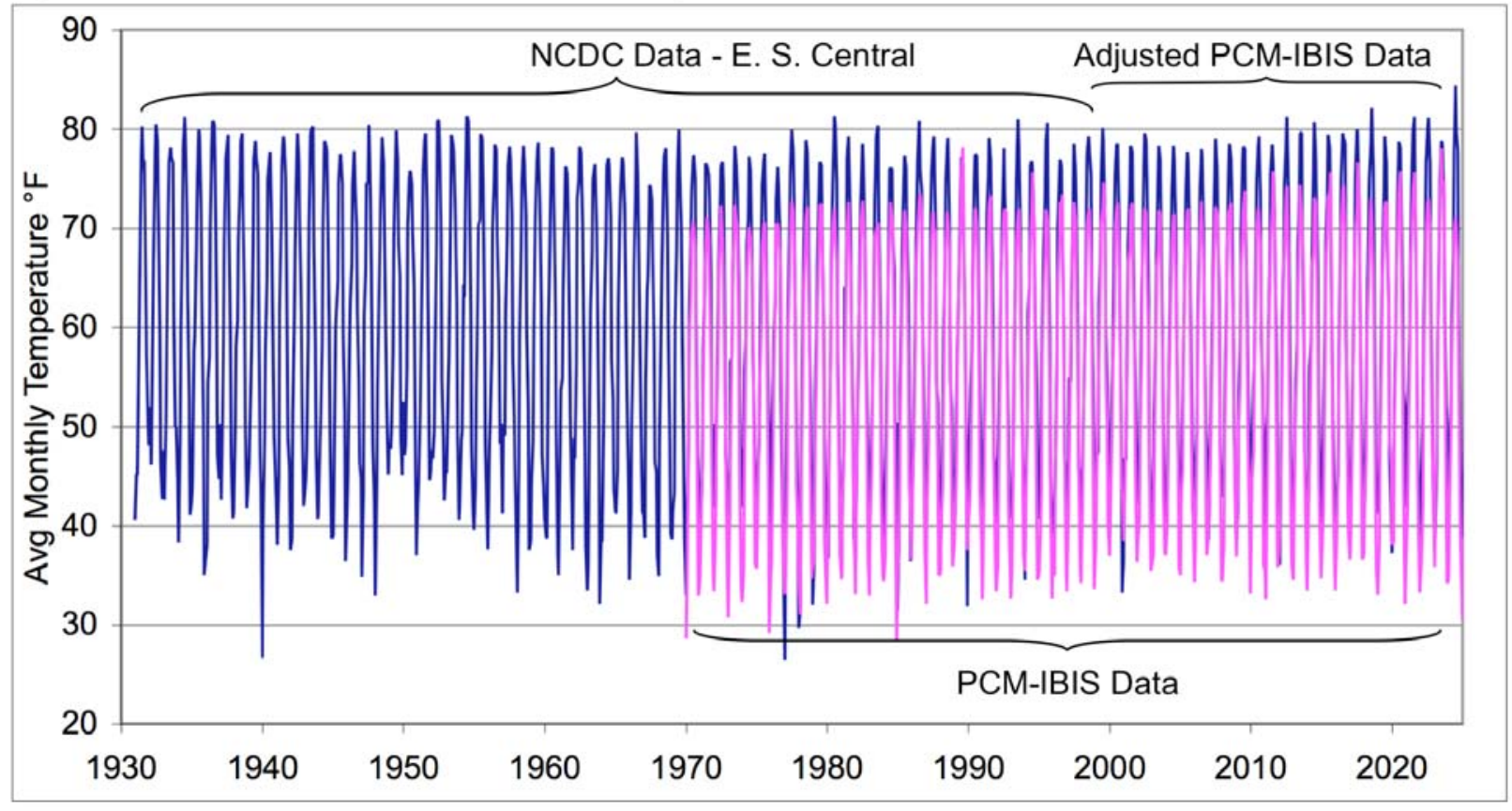

Figure 4 shows the resulting average temperatures for the Low- $\Delta \mathrm{T}$ scenario. The dashed lines are 1971-2000 average values calculated from NCDC degree-days and used in our Reference case. Using those temperature changes and the average degree-day values for 1971-2000 from NCDC, we could calculate the degree-day amounts for future years. Note that both heating and cooling needs could increase in any year for a region if the data shows both hotter summers and cooler winters, or the opposite could occur with a flatter temperature profile. 
Figure 4. Annual average temperature from NCDC (pre-2002) and adjusted from the PCM-IBIS low- $\Delta$ T scenario (post 2002). Dashed lines show the NCDC 1971-2000 averages.

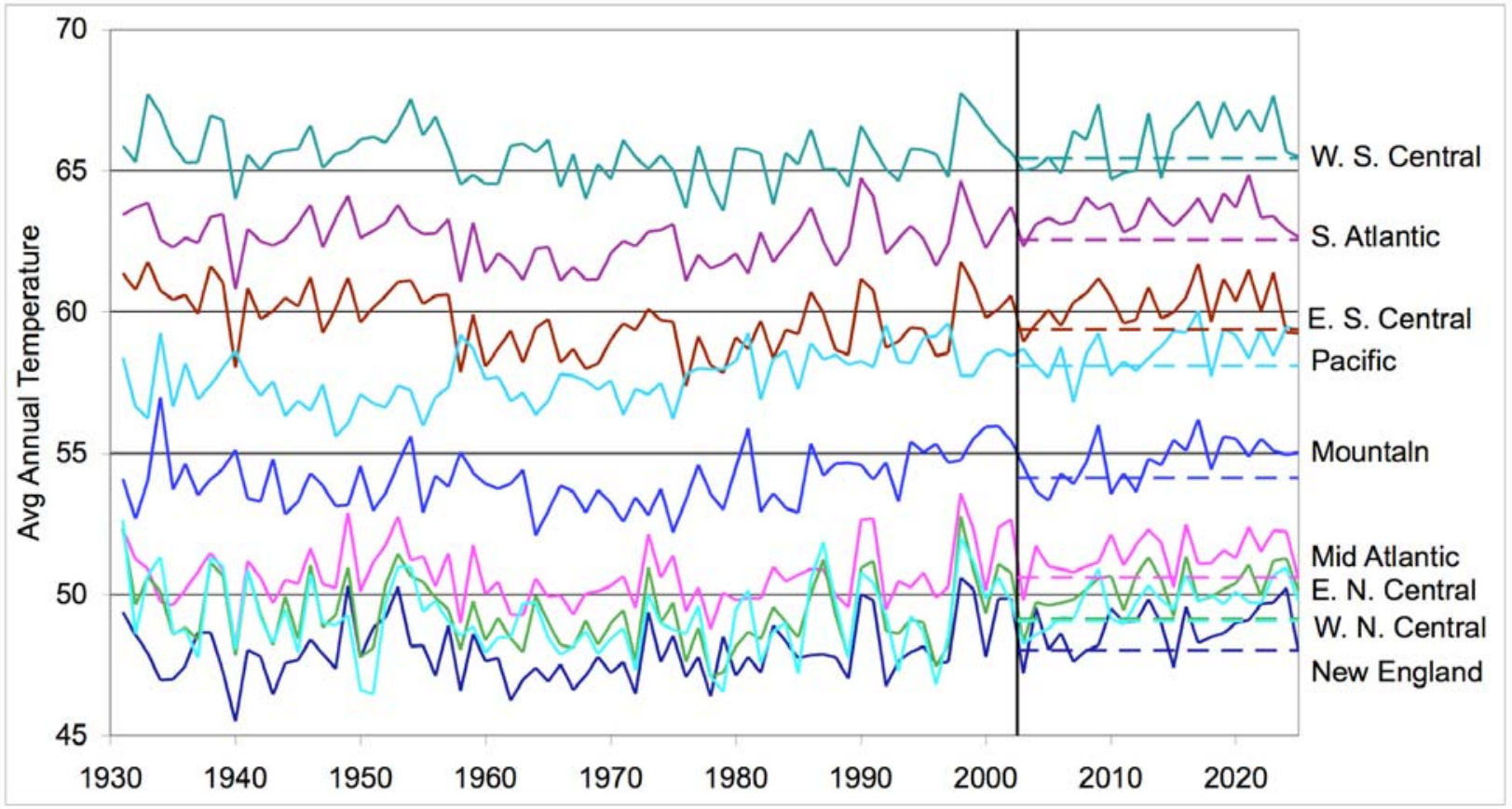




\section{The NEMS model}

\subsection{Overview}

Economic simulation involves modeling the economic decision-making of an energy-using sector or entire region. The stock of existing buildings and equipment, data on options available, decision procedures, energy prices, etc. need to be available for the model to attempt to realistically simulate the purchase behavior of people. Even with adequate data, there will always be disagreements on some of the more subjective criteria, such as importance of energy efficiency versus other product characteristics, or market inertia of consumers towards changing consumer preferences. However, economic simulation provides significant insights into the future energy market under changes to key parameters such as temperature.

The most widely recognized economic simulation model is the National Energy Modeling System (NEMS). The EIA developed this model to forecast national and regional energy supply and demand through 2025. The model allows a wide variety of parameters to be altered to determine their impact on overall fuel use. Examples include changes in equipment efficiencies, costs, fuel supplies, economic growth, and consumer preferences. Detailed information on the model can be found in the National Energy Modeling System: An Overview 2003 (EIA 2003b) and in the Assumptions for the Annual Energy Outlook 2003 (EIA 2003c). While this study is based on the version of the model used in the AEO2003, EIA has continued to modify and improve the model. More recent versions have incorporated the changes pioneered in this study to allow changes in future heating and cooling requirements.

NEMS models the major end-use sectors of the economy: residential, commercial, industrial, and transportation. Within the energy sector, it models electricity, oil, gas, coal, and renewable energy production. It separates the nation into nine geographical regions for analysis (Figure 2), providing regional information on energy and economic results.

Figure 5 from the NEMS Overview shows the overall flow of the NEMS model between the various sectors. Each module uses inputs from data sets provided by the user along with calculated values from the other modules in order to calculate its results. Because of the feedback between supply and demand, some internal iteration is required.

Global warming will have the largest energy-use impact through increases in temperatures. Additional cooling energy, but less heating energy, may be required. These factors are incorporated in the model using cooling degree-days and heating degree-days for the commercial and residential sectors in each region. Historical values from 1993 to the present are entered into the model for each of the nine regions. In the standard NEMS model, values for the years between the base year and 2020 are kept constant, but a variation in the model can be made to include increases or decreases to reflect changes in warming. 
Figure 5: National Energy Modeling System

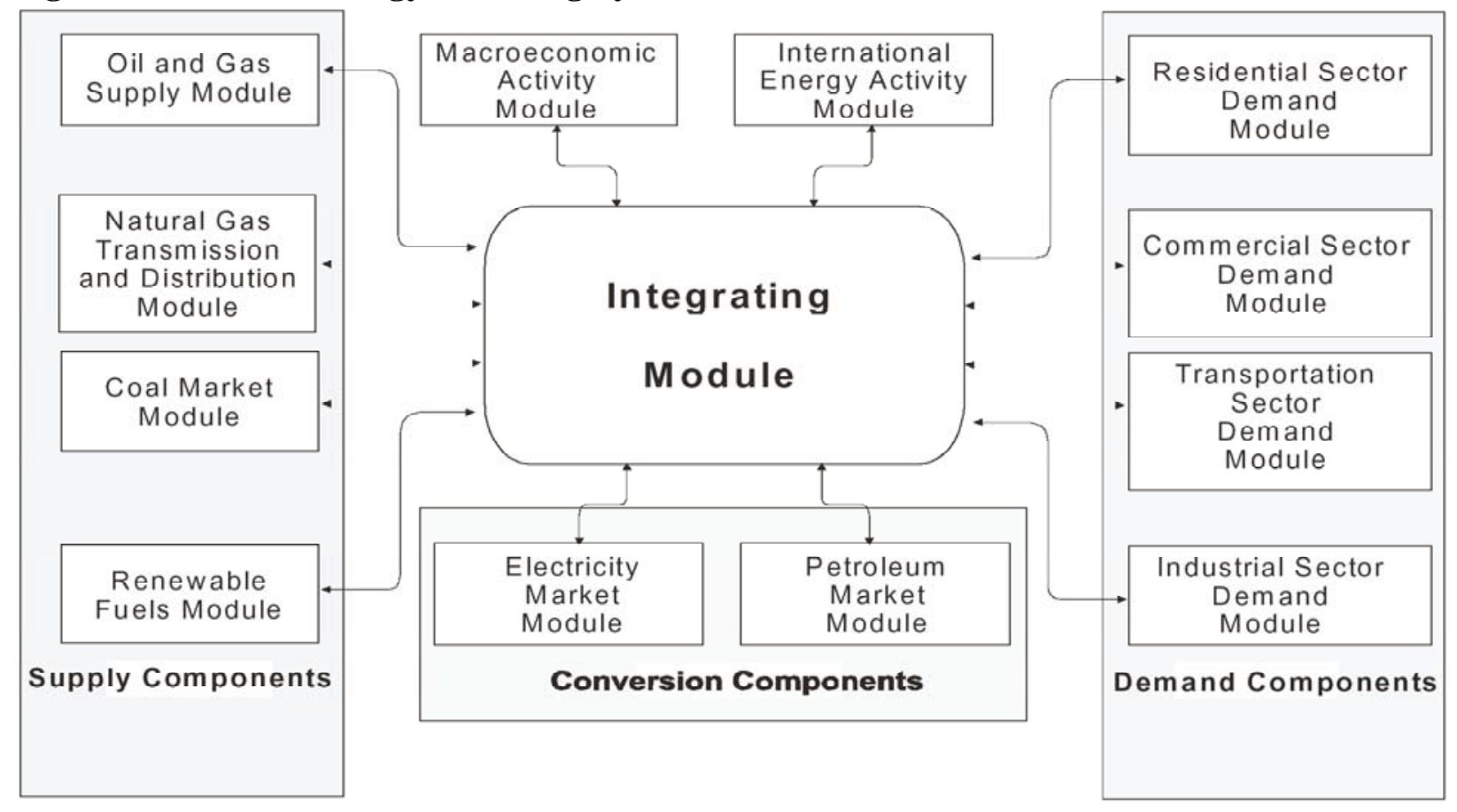

\subsection{Buildings Analysis}

The residential and commercial sectors are largely defined by the types of buildings used. The residential sector is split between single-family dwellings, multi-family dwellings, and mobile homes. The commercial sector is separated by the type of activities performed. NEMS models eleven different businesses: assembly, education, food sales, food service, health care, lodging, large office, small office, mercantile \& service, warehouse, and other. For each type of building NEMS maintains information on end-use service, fuel, equipment used, energy prices, customer purchasing preferences, age distribution of buildings, etc.

In the Residential sector, base year housing data, appliance types and efficiencies, and other data are provided by inputs from the user. Other NEMS modules provide information such as energy prices and economic growth. The module calculates housing stock, appliance needs, and distributed energy use to determine energy demands. These are then fed back to the other modules if they are to be called upon for recalculation, and to the output reports.

The commercial module operates similarly to the residential module, with exogenous data provided by the user and calculated values from the other modules. Floorspace and consequent end-services calculations are then made. Technology choices are determined, resulting in the energy use for each region and commercial building type.

\subsection{End-use equipment}

For each type of end-use service (heating, cooling, water heating, etc.) different technologies are available. The model maintains data on capital cost, efficiency, type of fuel used, purchase preference criteria, and dates of availability for each type of equipment. This allows the model to bring on new equipment and retire older equipment throughout the period of simulation. To 
bring on new equipment it calculates the life cycle cost of each technology, and selects a mixture based on the relative cost of each. The life cycle cost includes the capital (or replacement) cost plus future costs of the energy needed discounted using an input discount rate. The rates are higher than just the cost of money to reflect customer resistance or insensitivity to ongoing costs versus initial cost. In addition, the model places limits on the amount of technology or fuel switching for various types of customers, based on historical survey data from the EIA Residential Energy Consumption Survey (EIA 1999) and Commercial Buildings Energy Consumption Survey (EIA 2002).

Residential and commercial sectors have a number of end-uses modeled (Table 5 and Table 6). Each major end-use has a number of different technologies available. Within each technology (e.g., natural gas furnace) there may be many different types of equipment available at a variety of costs and efficiencies.

Besides the major end-uses modeled within NEMS, a "Miscellaneous Other" category is included. The Other category in the residential sector includes a variety of smaller end-uses, including, personal computers, color televisions, furnace fans, small kitchen appliances, other home electronics, and all of the other unidentified energy end-uses. It also includes adjustments to ensure that each region and sector's energy-use agrees with the totals as reported in EIA's State Energy Data Report (SEDS)(EIA 1997).

Within the commercial sector, the "Other" category contains transformers, traffic lights, exit signs, district services, automated teller machines, telecommunications equipment, medical equipment, and other unidentified end-uses. It also includes an adjustment term to ensure that the total commercial sector energy use adds up to the totals reported in EIA's SEDS (EIA 1997). 
Table 5: Services and Equipment in the NEMS Residential Sector Demand Module

\begin{tabular}{|ll}
\hline Space Heating Equipment & Cookstoves \\
Electric Furnace & Natural Gas \\
Electric Air-Source Heat Pump & LPG \\
Natural Gas Furnace & Electric \\
Natural Gas Other (Hydronic) & \\
Kerosene Furnace & Clothes Dryers \\
LPG Furnace & Natural Gas \\
Distillate Furnace & Electric \\
Distillate Other (Hydronic) & \\
Wood Stove & Refrigerators \\
Electric Ground-Source Heat Pump & 18 cubic-foot Top Mounted Freezer \\
Natural Gas Heat Pump & 24 cubic-foot Side-by-Side with \\
& Through-the-Door Features \\
Space Cooling Equipment & \\
Electric Room Air Conditioner & Water Heaters \\
Central Air Conditioner & Natural Gas \\
Electric Air-Source Heat Pump & Electric Resistance / Heat Pump \\
Electric Ground-Source Heat Pump & Distillate \\
Natural Gas Heat Pump & LPG \\
& Solar Thermal \\
Freezers & \\
Chest Manual Defrost & Lighting \\
Upright Manual Defrost & Incandescent \\
Clothes Washers & Compact Fluorescent \\
Vertical Axis & Halogen Tochiere \\
Horizontal Axis & \\
\hline
\end{tabular}

Table 6: Building types and end-use services in NEMS Commercial Demand Module

\begin{tabular}{|l|l|}
\hline Building Types & End-Use Services \\
\hline Assembly & Space Heating \\
Education & Space Cooling \\
Food Sales & Water Heating \\
Food Service & Ventilation \\
Health Care & Cooking \\
Lodging & Lighting \\
Office - Large & Refrigeration \\
Office - Small & Office Equipment - PCs \\
Mercantile \& Service & Office Equipment - Other \\
Warehouse & Other \\
\hline
\end{tabular}

\subsection{Decision-making}

With multiple versions of the various appliances available, NEMS must select the proportion of each for the various building types modeled. It calculates the expected cost to supply the services from each appliance, taking into account the expected cost of energy. It uses a logit formula to allocate market share based on the relative expected cost of the various equipment types that are available, with low cost equipment getting a higher-proportion of the market. To calculate the expected cost, it discounts future costs based on the ratio of two parameters that together define the required discount or "hurdle" rate for the equipment. Higher rates imply that future costs are less important to consumers as compared to the initial cost. 


\subsection{Modifications to NEMS for temperature}

Rather than a step increase in temperature, we had temperatures increase linearly between 2003 and 2025 within NEMS. This required some modification to the NEMS input data sets and to the source code. The reference NEMS model allows variations in the HDD and CDD through 2002, to reflect actual values. It then uses a single set of values for the following years, implying a normal temperature over the period. We changed the FORTRAN code so that it would also incorporate values for each of the future years, and use those values in calculating the cost of heating and cooling in the residential and commercial sectors. The industrial sector temperaturedependent calculations were not modified for this analysis.

A reference case was established that was based on the values from the Annual Energy Outlook 2003. Then two cases were run: one with a one-degree increase in temperatures by 2025 and one with a three-degree rise. The amount of energy, cost, and other results were compared between the cases. To keep historical year results consistent in all cases, we used EIA's values for HDD and CDD through 2002 and for 2003, we used the mean values as determined by the NCDC data sets (Table 1 and Table 2). The values for 2025 were set based on the amount of warming for the scenario $\left(1^{\circ}\right.$ or $\left.3^{\circ} \mathrm{F}\right)$, and values for the intervening years were interpolated between the 2003 and 2025 values for each region.

DD-NEMS was run with eight full iterations, allowing supplies, demands, and prices to equilibrate. For this analysis, we ran five cases through DD-NEMS:

- The Reference case with the post-2002 degree-days based on the NCDC 1971-2000 average,

- A scenario with temperatures increased by $1^{\circ} \mathrm{F}$ by 2025 ,

- A scenario with temperatures increased by $3^{\circ} \mathrm{F}$ by 2025 ,

- A scenario with temperatures varying by year according to the results from the PCM-IBIS run with low sensitivity to greenhouse gases,

- A scenario with temperatures varying by year according to the results from the PCM-IBIS run with high sensitivity to greenhouse gases. 


\section{Results of fixed warming in NEMS}

To show how temperatures influence energy use, cost, and carbon emissions, we present a series of analyses. Temperature changes show up initially in the heating and cooling demands for commercial and residential buildings. In NEMS, these demands get converted into primary energy demands, which takes into account the energy losses associated with generating electricity. These losses occur because most of the thermal energy (heat) is exhausted from the generating facility.

The net result on the end-use demand and primary demand will be different because of this difference; electricity is used much more heavily for cooling than heating, so net primary energy will be more, to reflect the increase in cooling needs. Figure 6 shows the heating and cooling end-use and primary energy amounts with the $3^{\circ} \mathrm{F}$ rise in temperature. Note the smooth change in demands over time. The direct effect of temperature both raises and lowers energy use so that there is a subtraction between two large numbers resulting in a small number.

\section{Figure 6. Change in Building Heating and Cooling Energy with $3^{\circ} \mathbf{F} \Delta \mathbf{T}$}

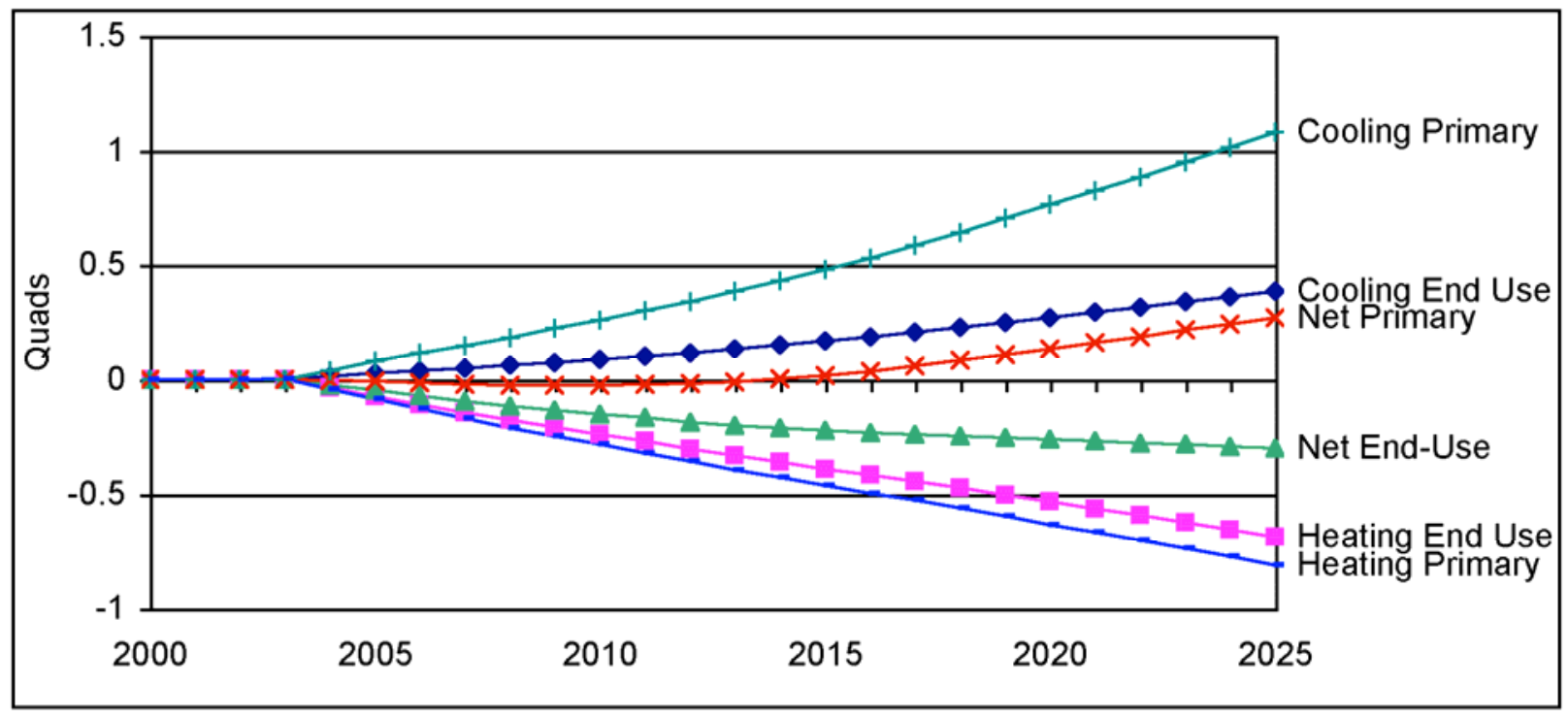

The $1^{\circ} \Delta \mathrm{T}$ scenario has similar results as the $3^{\circ} \Delta \mathrm{T}$ scenario, but, as expected, about one-third the level. Figure 7 shows the net end-use and primary energy results for both the $3^{\circ}$ case (also in Figure 6 above) and the $1^{\circ} \Delta \mathrm{T}$ case. Both the end-use and primary energy amounts reflect the temperature proportions. The net primary energy for the $1^{\circ} \Delta \mathrm{T}$ scenario is little different from the reference scenario. 
Figure 7. Heating and Cooling Net Changes with $1^{\circ}$ and $3^{\circ} \Delta T$

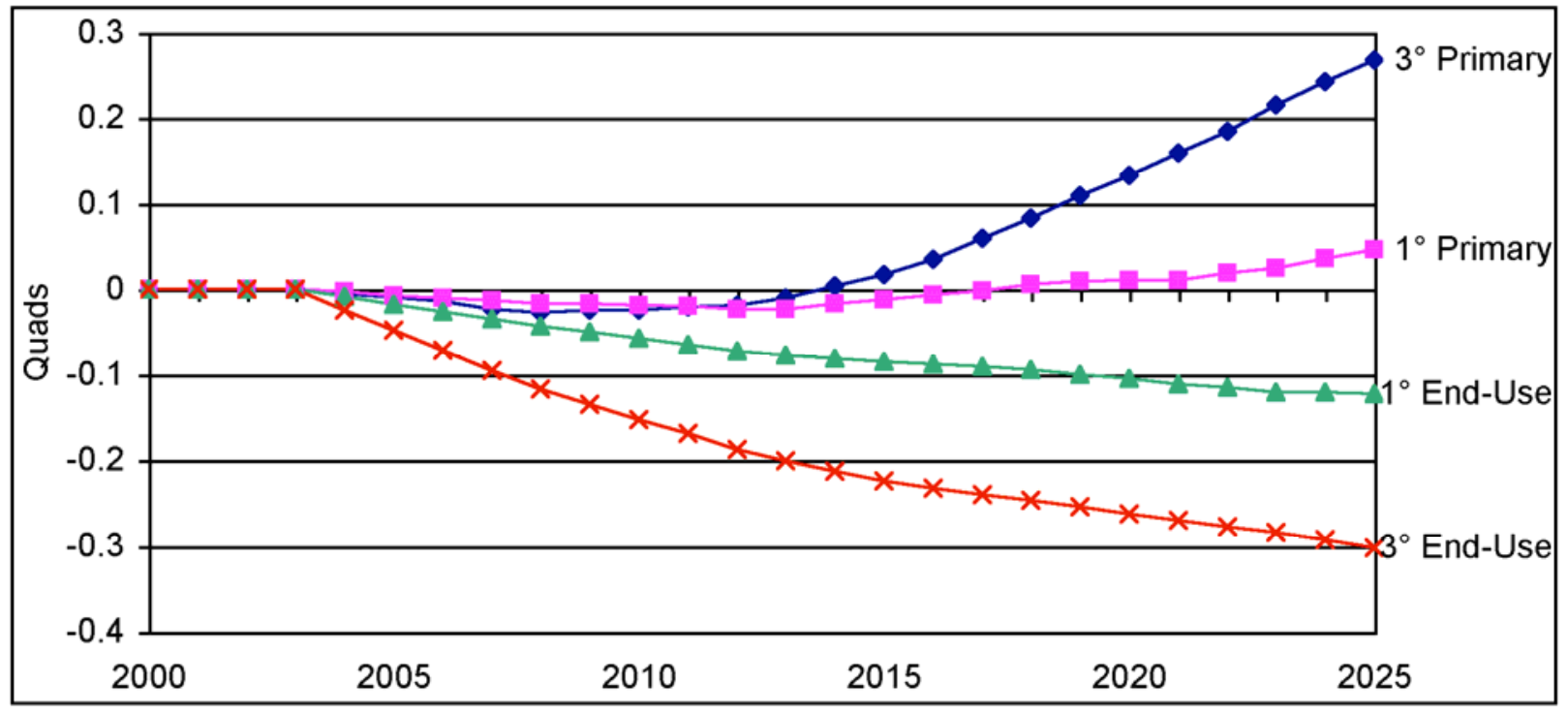

Within NEMS, there are other factors that contribute to energy changes. Besides small changes in end-uses due to changes in income levels and prices, the efficiency of electricity production can change as new plants are built. For example, Table 7 shows the end use (delivered) and primary energy changes in the residential sector for 2025 from the reference and $3^{\circ} \Delta \mathrm{T}$ scenarios. It also shows the difference in the two, both in Quads and as a percentage of Reference amount for that end-use. There is a $6 \%$ decrease in heating needs and a $25 \%$ increase in cooling needs. The other end-uses have very small changes, especially in the delivered energy amounts.

Table 7. Residential Energy Use in 2025 for the Reference and $3^{\circ} \Delta \mathrm{T}$ Scenarios (Quads)

\begin{tabular}{|l|rrrr|rrrr|}
\hline & \multicolumn{4}{|c|}{ Delivered Energy by End-Use } & \multicolumn{4}{c|}{ Primary Energy by End-Use } \\
& Reference & $3^{\circ} \Delta \mathrm{T}$ & Change & \multicolumn{1}{c|}{$\%$} & Reference & $3^{\circ} \Delta \mathrm{T}$ & \multicolumn{1}{c|}{ Change } & $\%$ \\
\hline \hline Space Heating & 6.25 & 5.88 & -0.378 & $-6.0 \%$ & 7.25 & 6.79 & -0.456 & $-6.3 \%$ \\
Space Cooling & 0.68 & 0.85 & 0.173 & $25.3 \%$ & 1.98 & 2.47 & 0.493 & $24.9 \%$ \\
Water Heating & 2.26 & 2.26 & 0.003 & $0.1 \%$ & 3.09 & 3.09 & -0.005 & $-0.2 \%$ \\
Refrigeration & 0.33 & 0.33 & 0.000 & $0.0 \%$ & 0.96 & 0.96 & -0.003 & $-0.4 \%$ \\
Cooking & 0.40 & 0.40 & 0.000 & $0.0 \%$ & 0.64 & 0.64 & -0.001 & $-0.2 \%$ \\
Clothes Dryers & 0.38 & 0.38 & -0.001 & $-0.2 \%$ & 0.91 & 0.90 & -0.005 & $-0.6 \%$ \\
Freezers & 0.09 & 0.09 & 0.000 & $0.0 \%$ & 0.27 & 0.27 & -0.001 & $-0.4 \%$ \\
Lighting & 1.07 & 1.07 & -0.002 & $-0.2 \%$ & 3.10 & 3.09 & -0.016 & $-0.5 \%$ \\
Clothes Washers & 0.03 & 0.03 & 0.000 & $0.0 \%$ & 0.08 & 0.08 & 0.000 & $-0.4 \%$ \\
Dishwashers & 0.03 & 0.03 & 0.000 & $0.0 \%$ & 0.08 & 0.08 & 0.000 & $-0.4 \%$ \\
Color Televisions & 0.27 & 0.27 & 0.000 & $-0.1 \%$ & 0.77 & 0.77 & -0.004 & $-0.5 \%$ \\
Computers & 0.11 & 0.11 & 0.000 & $0.0 \%$ & 0.33 & 0.33 & -0.001 & $-0.4 \%$ \\
Furnace Fans & 0.11 & 0.11 & 0.000 & $-0.1 \%$ & 0.31 & 0.31 & -0.001 & $-0.5 \%$ \\
Other Uses 7/ & 2.09 & 2.08 & -0.005 & $-0.2 \%$ & 5.64 & 5.61 & -0.034 & $-0.6 \%$ \\
\hline Total Energy & 14.10 & 13.88 & -0.211 & $-1.5 \%$ & 25.42 & 25.38 & -0.036 & $-0.1 \%$ \\
\hline
\end{tabular}

However, there is an added factor at play here. Despite electricity end-uses only having decreases of $0.0 \%$ to $0.2 \%$, the primary energy use went down $0.4 \%$ to $0.6 \%$. This is because the added electricity requirements meant more new plants were built and the average efficiency of 
electricity production rose from $34.4 \%$ to $34.5 \%$. So despite the increase in net energy needs for heating and cooling, the overall residential primary energy need is lower. The commercial sector has a similar result except the total primary energy use is positive even with the savings due to improved efficiency. The industrial and transportation sector also have small declines because of the interplay of end-uses, prices and efficiencies. The net result for all sectors is that, because of the offset of heating and cooling demands resulting in a small number, the other factors end up being significant, as shown in Figure 8.

Figure 8. Primary Energy Use Differences between the Reference and $3^{\circ} \Delta \mathrm{T}$ Scenarios

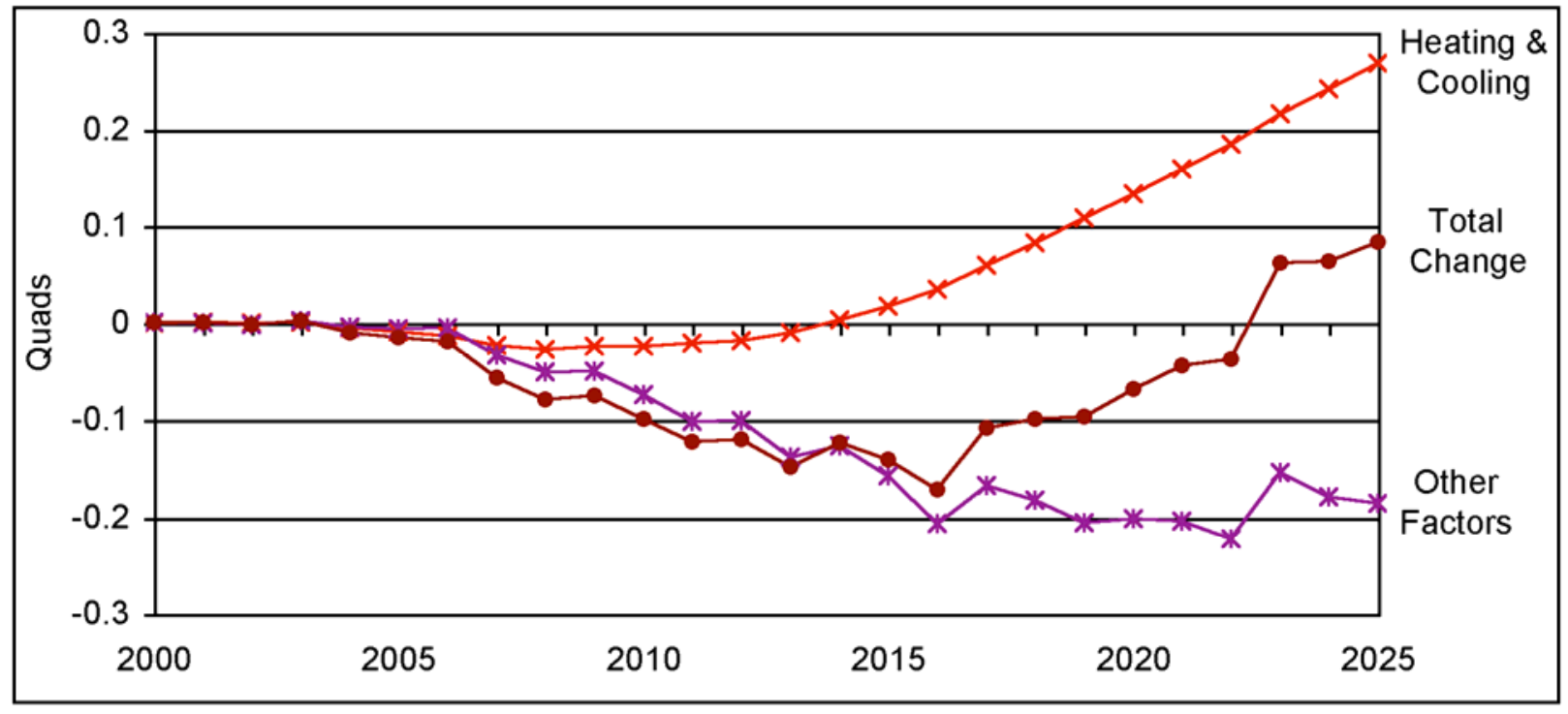

NEMS calculates prices for each energy source, and so a consequent cost impact can be estimated. In the $3^{\circ} \Delta \mathrm{T}$ scenario, energy costs over the next twenty years are $\$ 36$ billion more than in the reference scenario. The $1^{\circ} \Delta \mathrm{T}$ scenario has an increase of $\$ 7$ billion. Most of the extra cost ( $\$ 28$ billion) in the $3^{\circ} \Delta \mathrm{T}$ scenario is in the years $2007-2017$ when electricity prices were $1 \%$ higher because of changes in the electricity market.(Figure 9) 
Figure 9: Change in energy cost with increase in average temperature

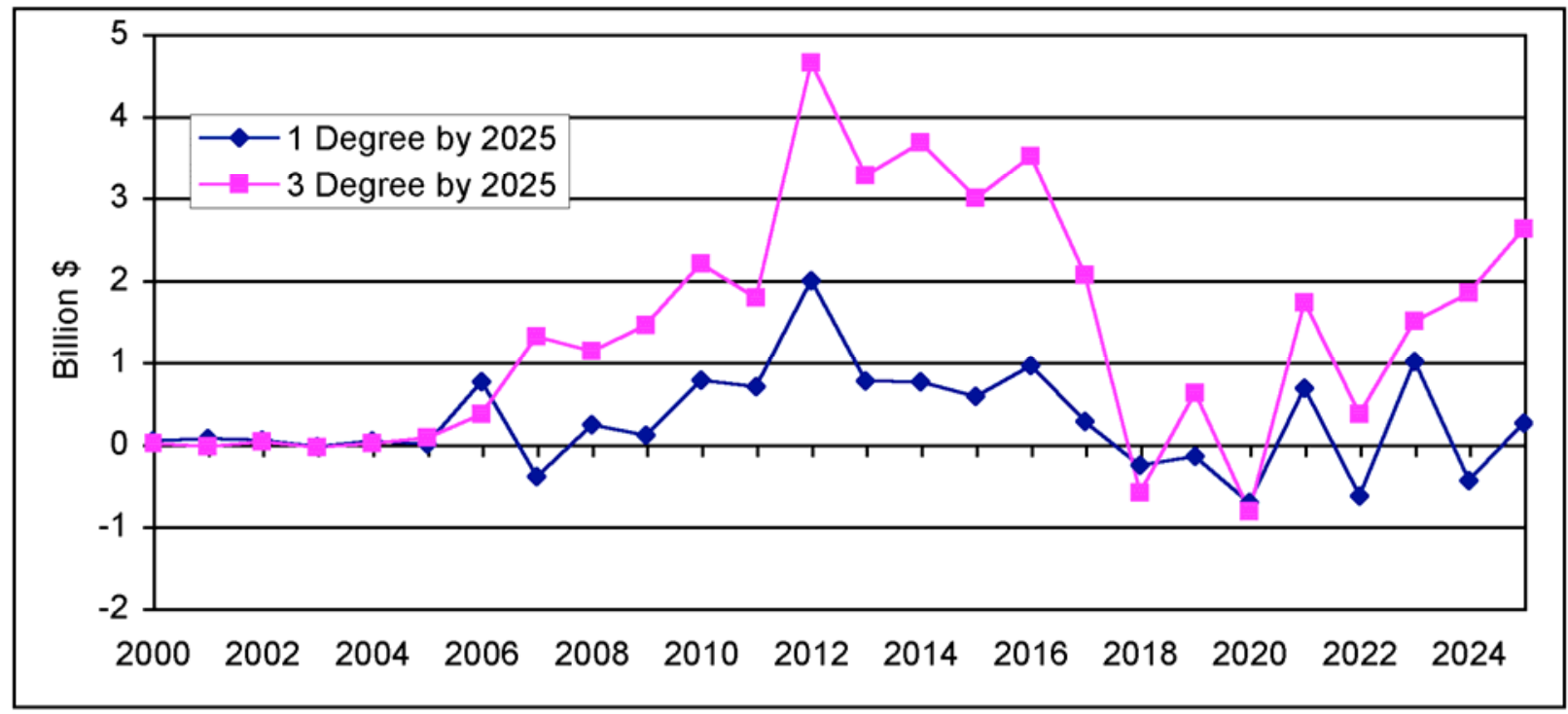

In all of our simulations carbon emissions initially decline with reduction in net primary energy, but begin increasing by year 2015 (Figure 10, cf. Figure 31). With continued warming, primary energy needs for cooling grow in proportion to those for heating, thereby becoming more influential. Eventually, additional primary energy needed for cooling approaches the magnitude of the savings in primary energy for warming, and because the fuel mix for meeting cooling demand emits the greater amount of carbon per unit of primary energy, a balance is achieved. Further warming then results in increasing carbon emissions.

Figure 10. Change in carbon emissions with increase in average temperature

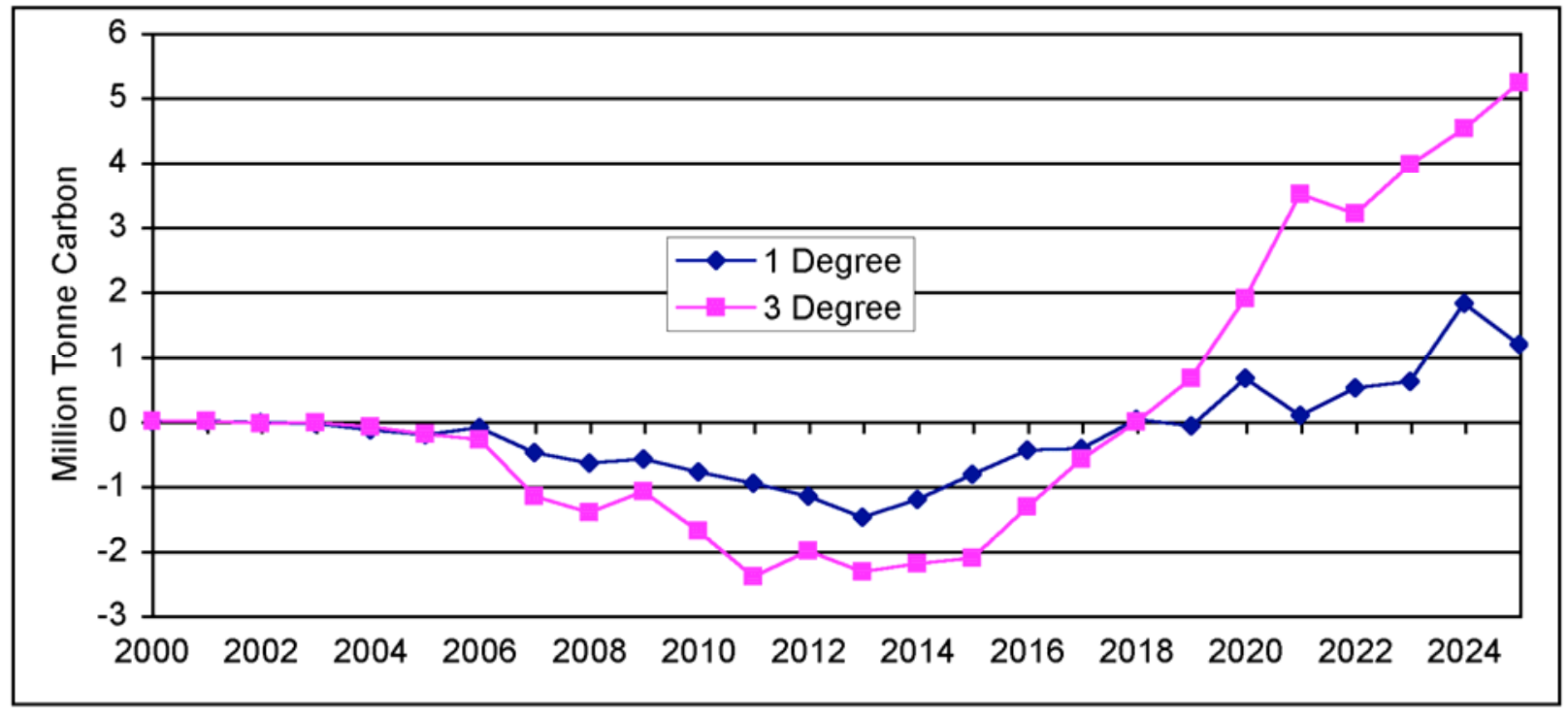




\section{Results Using PCM-IBIS with Low Temperature Response}

\subsection{Regional Energy Use Change}

The United States is a cool country. Nationally, there is over three times as much energy used for heating as for cooling (Table 8). For New England the ratio of cooling to heating is as low as $8 \%$, while only in the W.S. Central do cooling needs approach heating at $91 \%$. As a consequence, even if cooling requirements increase by a relatively high percentage, they can be swamped by the reduction in heating.

Table 8. Reference scenario heating and cooling primary energy use 2003-2025 (Quads)

\begin{tabular}{|l|crrrrrrrrr|}
\hline & $\begin{array}{c}\text { New } \\
\text { England }\end{array}$ & $\begin{array}{c}\text { Mid } \\
\text { Atlantic }\end{array}$ & $\begin{array}{c}\text { E. N. } \\
\text { Central }\end{array}$ & $\begin{array}{c}\text { W. N. } \\
\text { Central }\end{array}$ & $\begin{array}{c}\text { S. } \\
\text { Atlantic }\end{array}$ & $\begin{array}{c}\text { E. S. } \\
\text { Central }\end{array}$ & $\begin{array}{c}\text { W. S. } \\
\text { Central }\end{array}$ & Mountain & Pacific & $\begin{array}{c}\text { National } \\
\text { Total }\end{array}$ \\
\hline Heating Energy & 15.1 & 37.5 & 50.7 & 20.9 & 31.7 & 13.8 & 14.6 & 15.6 & 23.0 & 223.0 \\
Cooling Energy & 1.2 & 5.3 & 8.5 & 4.7 & 19.4 & 7.8 & 13.3 & 5.1 & 5.0 & 70.2 \\
Ratio Cool/Heat & $8 \%$ & $14 \%$ & $17 \%$ & $23 \%$ & $61 \%$ & $57 \%$ & $91 \%$ & $32 \%$ & $22 \%$ & $31 \%$ \\
\hline
\end{tabular}

The most direct impact of temperature change on US energy use is the heating and cooling requirements for residential and commercial buildings. Each region will have different changes depending on the amount of heating and cooling needed as compared to the long-run average used in the base case. In general, the more northern regions of the country have a larger decrease in end-use heating needs than an increase in their cooling needs (Figure 11). The values shown are the sum of the change in end-use energy through 2025. The East-North Central region (mainly the Great Lakes states) has the largest overall decrease in energy, because of both its relative climate and large population. The West-South Central region shows a net increase in end-use energy as increased cooling requirements outweigh heating reductions.

Figure 11. Cumulative change in end-use heating and cooling energy between by 2025 with varying degree-days vs. constant degree-days.

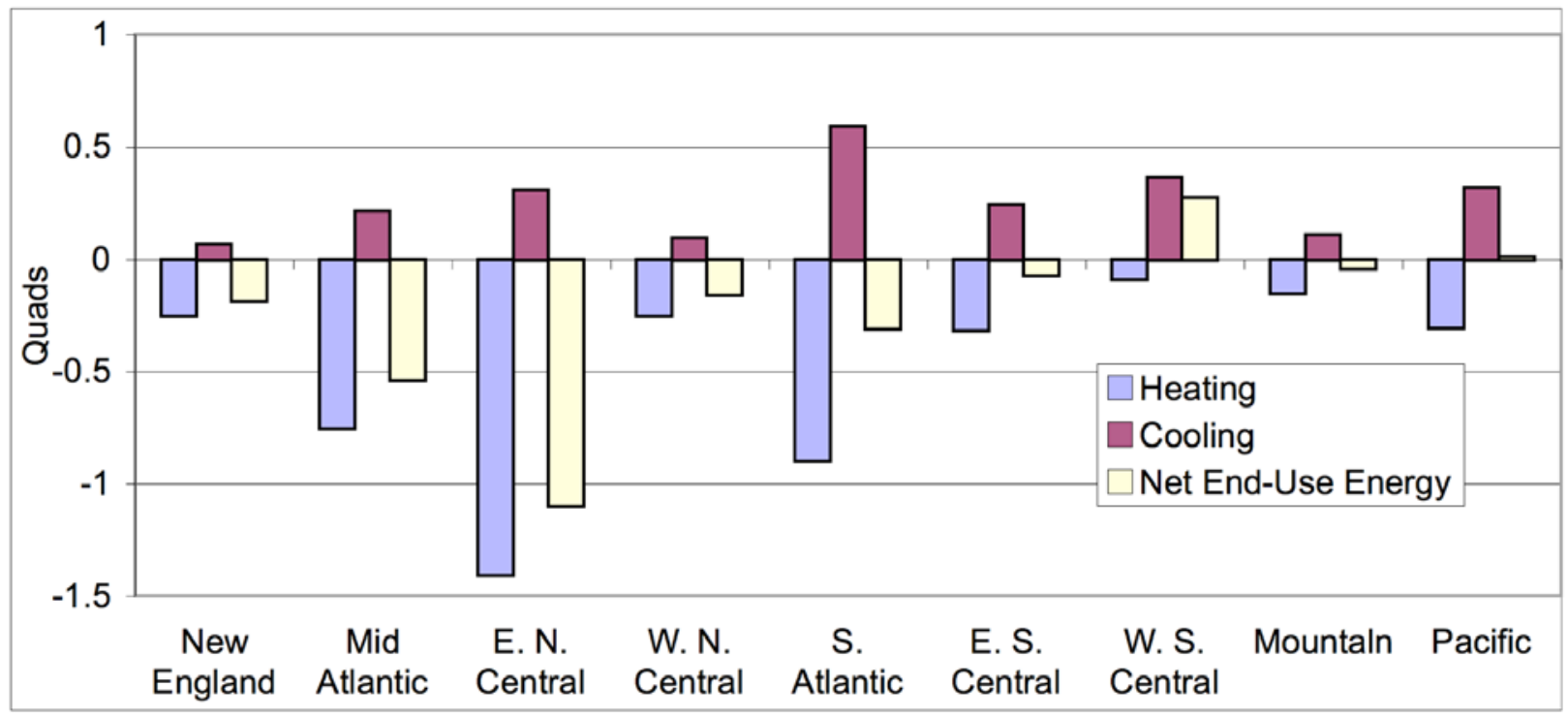

While end-use energy changes show the direct impact of temperature changes, the change in primary energy (which includes energy losses during electricity generation) is also important. 
Since electricity is used more for cooling than heating, the primary energy (the initial source of energy such as coal, oil, or gas) will change by a different amount than the end-use energy requirements. When adjustment for primary energy is added to each region, the net change in primary energy is positive for all but the northeastern regions (Figure 12). The southern regions (S. Atlantic, E. S. Central, and W. S. Central) have the largest change, likely due to the high penetration of air conditioning in these regions.

Figure 12. Cumulative change in primary heating and cooling energy between by 2025 with varying degree-days vs. constant degree-days.

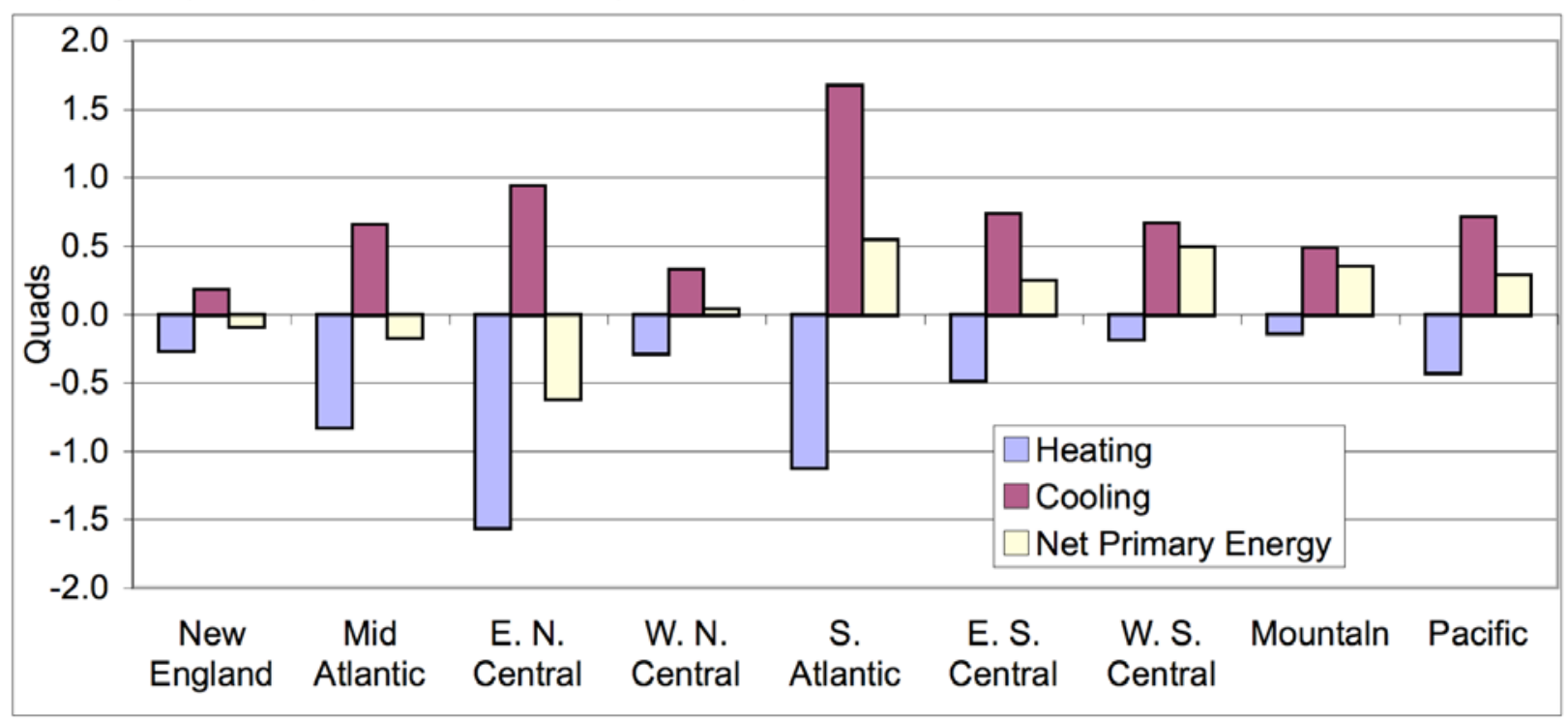

Comparing the end-use and primary energy use over time (Figure 13), there is relatively little heating provided by electricity so there is little difference between end-use and primary energy. Cooling on the other hand is largely provided by electricity, with associated large losses during the electricity generation from primary energy. The peaks and valleys in the curves reflect the changes in temperatures in the specific PCM-IBIS case used for this analysis. 
Figure 13. National change in heating and cooling end-use and primary energy amounts

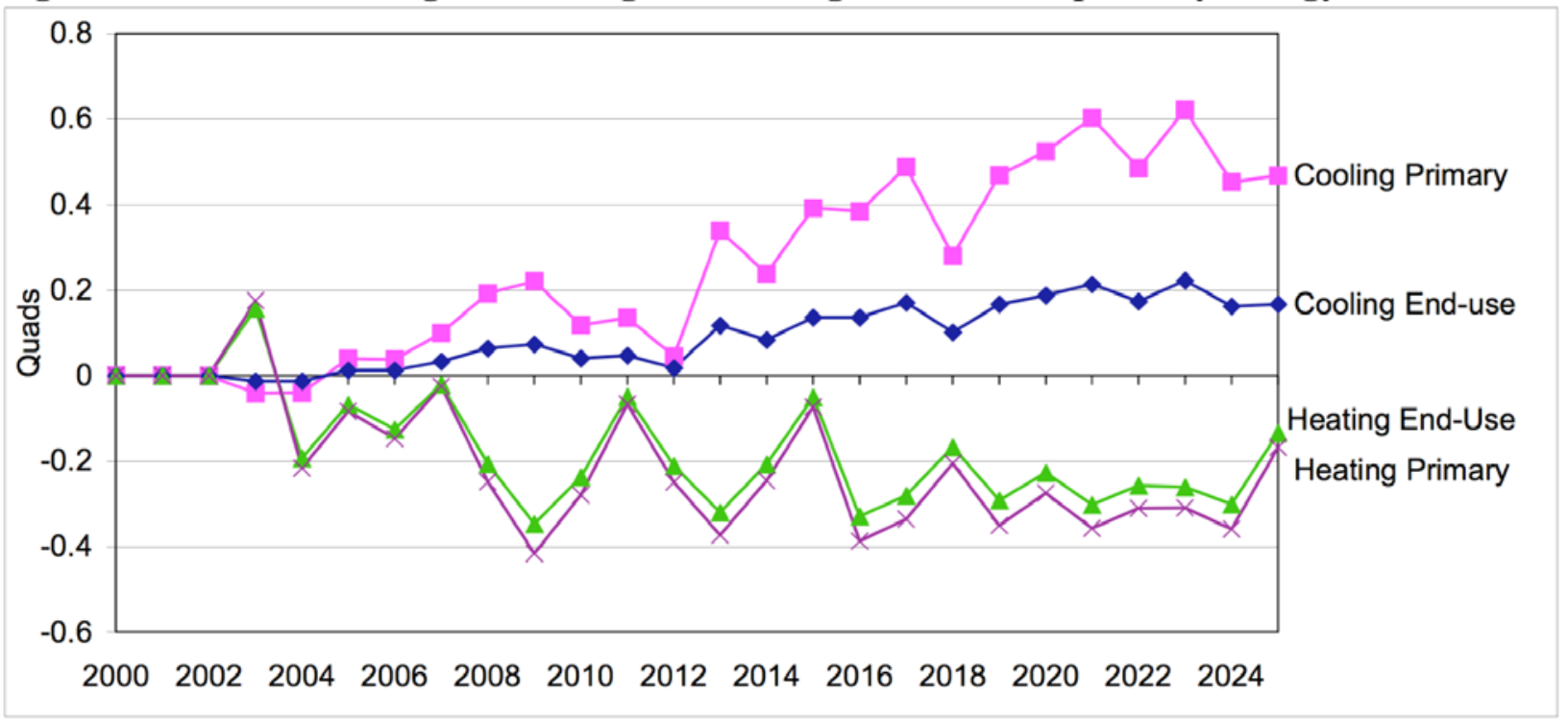

Increases in heating energy requirements in 2011 and 2015 reflect drops in temperatures for several of the regions. The gradual increase in cooling requirements reflects the rise in cooling degree-days. In addition, DD-NEMS shows a small impact in follow-on years from degree-day changes in previous years. This may reflect the modeling of decision-making on equipment penetration or generating plant construction, or may be an artifact of the code not reflecting the volatility of changes solely for temperature swings.

One interesting factor from Figure 13 is the early decline in heating needs that stabilizes around 0.3 Quads, while cooling needs continue to rise fairly consistently over the whole period. Those regions that most use space cooling will be most sensitive to the rise in cooling. In the next set of figures we show the change in primary energy for heating and cooling as a percentage of the primary energy used for heating and cooling in the base case. These reveal the relative impact of the energy change on each region's total energy use for these purposes.

The first four regions, in the northeast and central part of the U.S., show little change in energy use for most of the study period (Figure 14), with most fluctuations within $2 \%$ of the base amount. The Mid-Atlantic region (NJ, NY, PA) and W. N. Central region (IA, KS, MN, MO, $\mathrm{NE}, \mathrm{ND}, \mathrm{SD}$ ) show a slight trend towards increasing net energy use over the study period. New England (CT, ME, MA, NH, RI, VT) and the E. N. Central states (IL, IN, MI, OH, WI) have lower and less variable energy needs. Air conditioning is not as widespread in these regions so cooling changes have less impact. Warmer winter's lower heating requirements outweigh the summer air conditioning needs. 
Figure 14. Change in net primary energy use for heating and cooling in the northern and northeastern regions

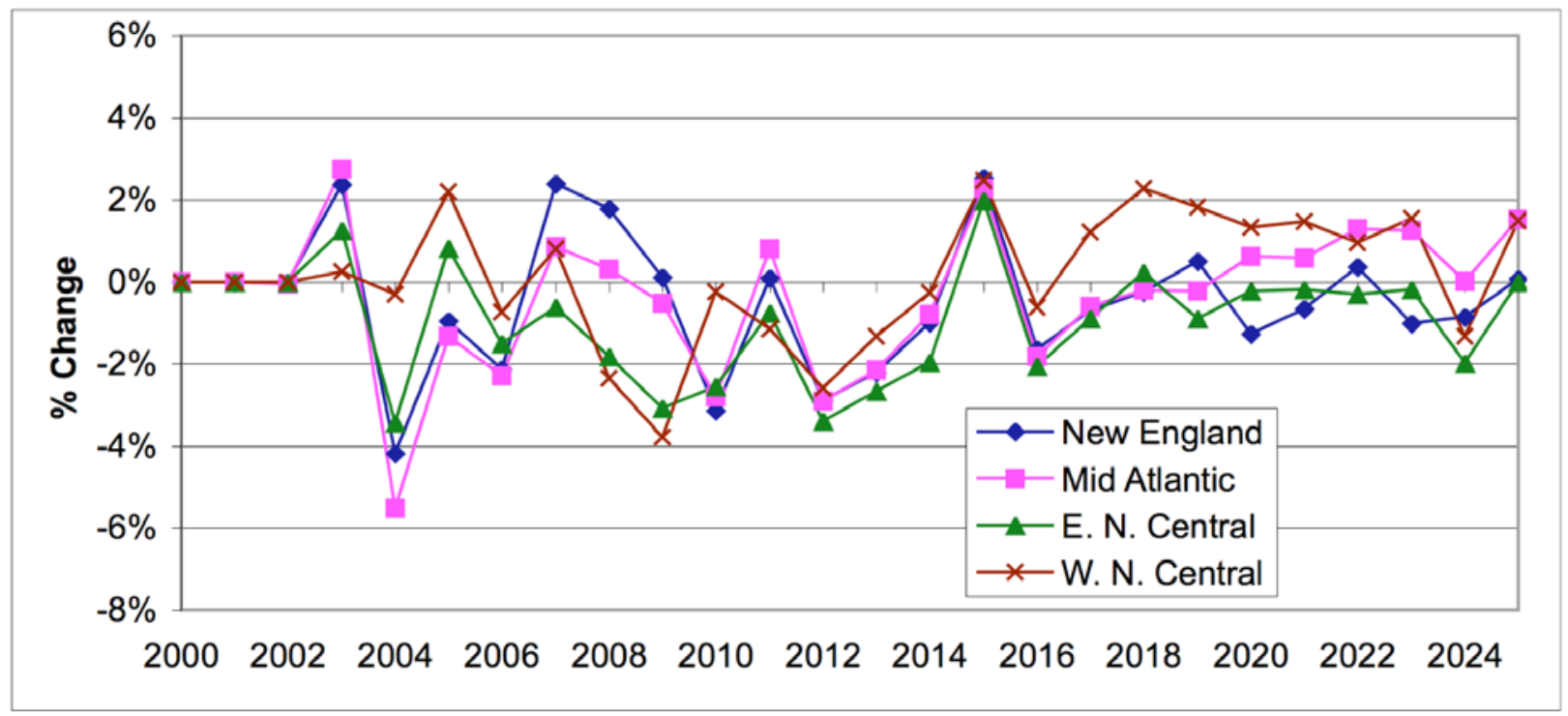

In Figure 15, the three regions covering the southern states show a definite trend of increasing energy needs in the latter part of the study period, with net primary energy use increasing by as much as $8 \%$ in 2023. The W. S. Central region (AR, LA, OK, TX) is the region that has the largest net increase in end-use energy needs (Figure 11). The E. S. Central region (AL, KY, MS, TN) has large early increases in energy needs; over the whole period, that region has energy use increasing over $4 \%$, with peaks over $8 \%$. All values past 2010 are higher than if there were no change in degree-days over time. The S. Atlantic region (DE, DC, FL, GA, MD, NC, SC, VA, WV) shows a more steady increase over the period.

Figure 15. Change in net primary energy use for heating and cooling in the southern regions

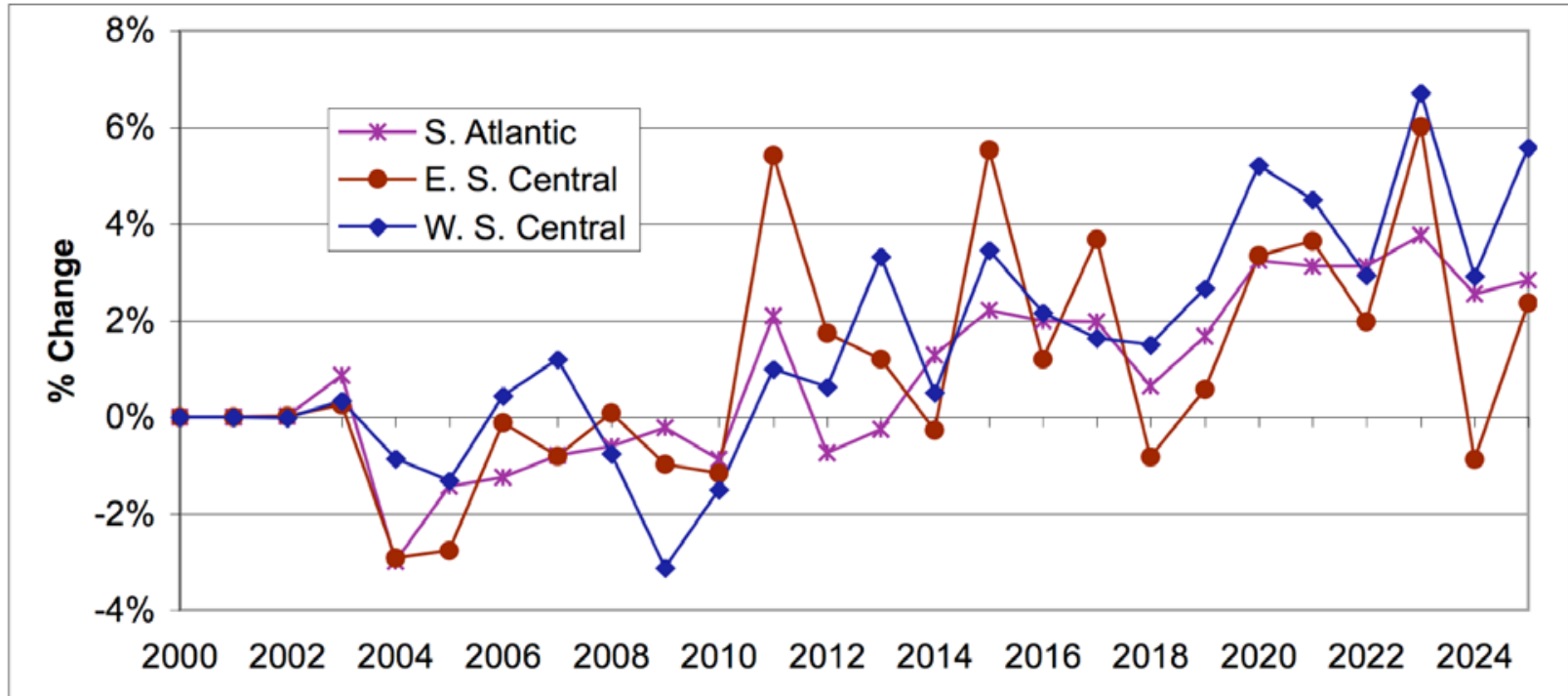


The last set of regional curves shows the western states and national average change (Figure 16). The Mountain region (AZ, CO, ID, MT, NV, NM, UT, WY) shows a relatively steady after 2010, while the Pacific region (AK, CA, HI, OR, WA) is relatively consistent in the $0 \%$ to $4 \%$ range. Note that the temperature analysis from PCM-IBIS does not include Alaska because of large area compared to population. The National change is also shown, with energy use around $2 \%$ higher by the end of the study period.

Figure 16. Change in net primary energy use for heating and cooling in the western regions and Nationally

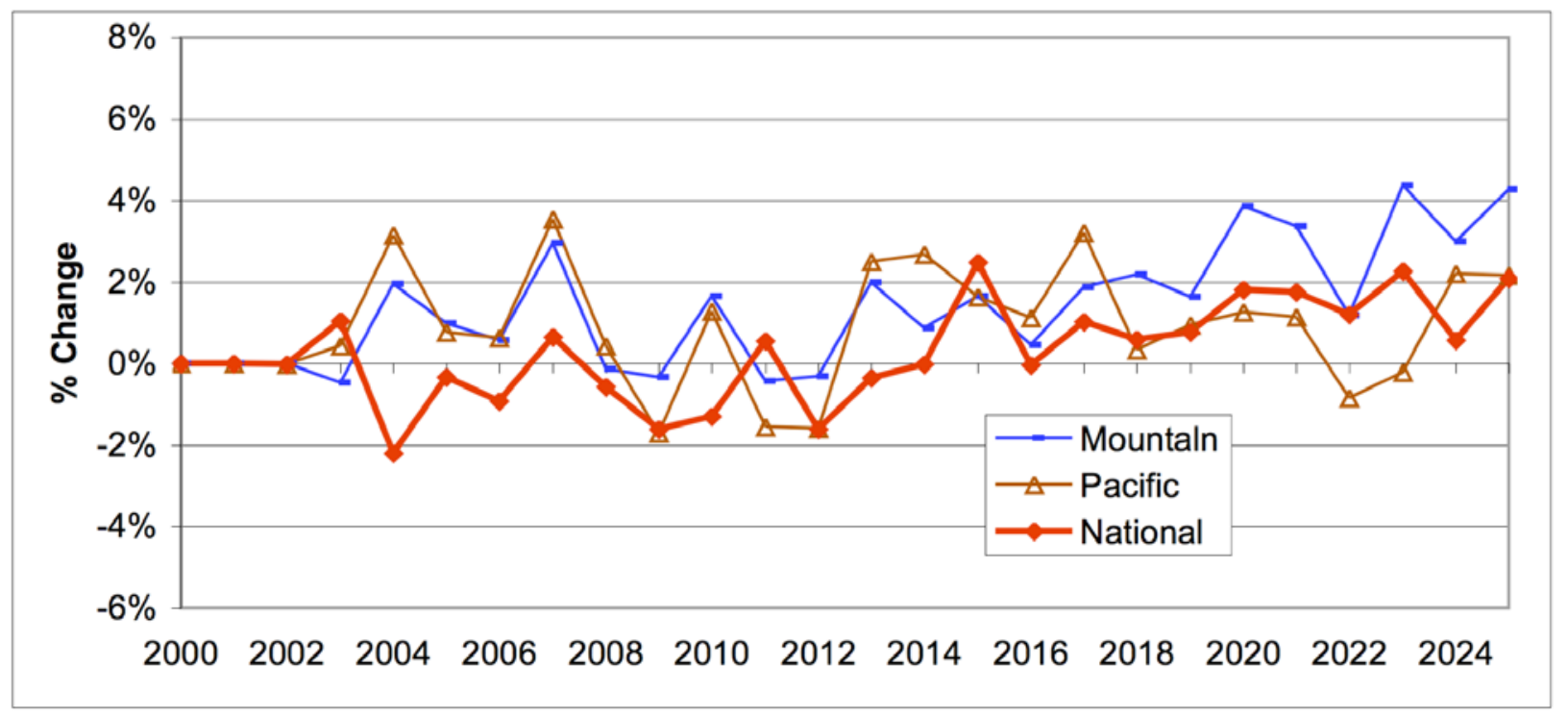

\subsection{Changes by sector and fuel}

Because of the changes in energy use for heating and cooling, the supplies and prices for other energy uses will also change, which can in turn change the energy demands for non-heating and cooling uses. These will generally be secondary to the change in heating and cooling, but since these latter two are opposite and so cancel each other out, the other uses become significant to the change in total energy use (Figure 17). Because DD-NEMS is a fully integrated model, the supplies and price changes flow to all sectors. Energy reductions in the other sectors, when combined, serve to moderate the net energy increase from space conditioning in the residential and commercial sectors. 
Figure 17. Change in national primary energy use for heating, cooling, other sectors, and total

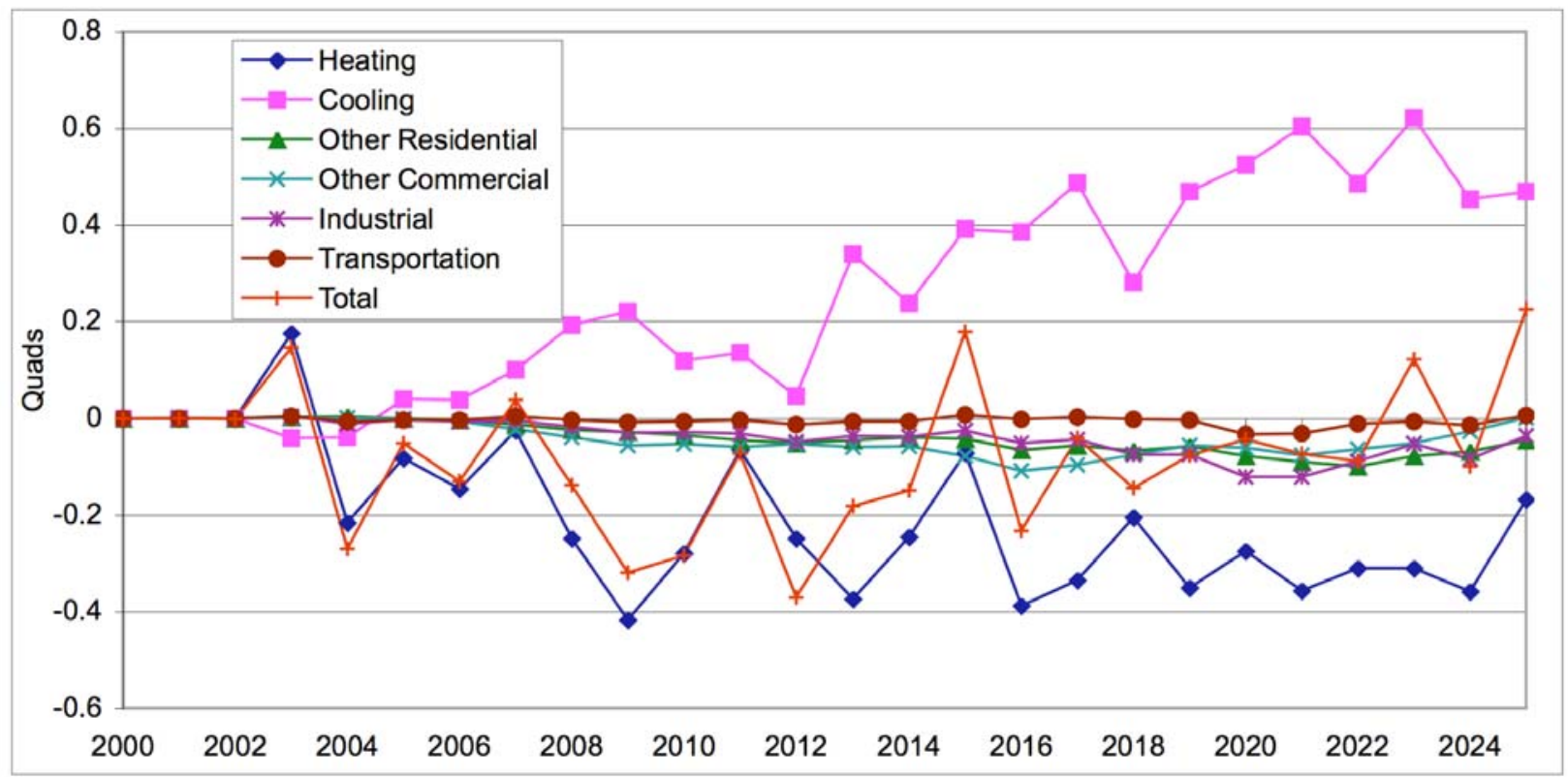

The change in demands for energy will vary by the type of energy. Heating is provided by several energy sources such as natural gas, heating oil, biomass, as well as electricity. Cooling, however, is almost entirely provided by electricity, which can come from coal, nuclear, oil, gas, hydro, or renewable sources. An increase in cooling will increase the electricity demand, which in turn will increase the number of power plants built. Depending on the economics in the region of the country where the power is needed, different types of power plants will be called for. Cross-trading between regions will also influence the type and amount of plants added. As shown in Figure 18, nationally there is an increase in coal consumption and decrease in natural gas. The natural gas change is influenced both by the increase for electricity that is more than offset by the decrease for heating. The other fuels (not shown) have relatively little change. Note that in 2025 energy use changes significantly. Figure 4 indicates that the PCM-IBIS data had temperatures dropping in that year (note the drop in average temperatures on the far-right of the first graph, especially in the northeastern regions). In such a situation, natural gas for heating would increase while coal use for electricity decline. 
Figure 18. Change in national energy supply by fuel type

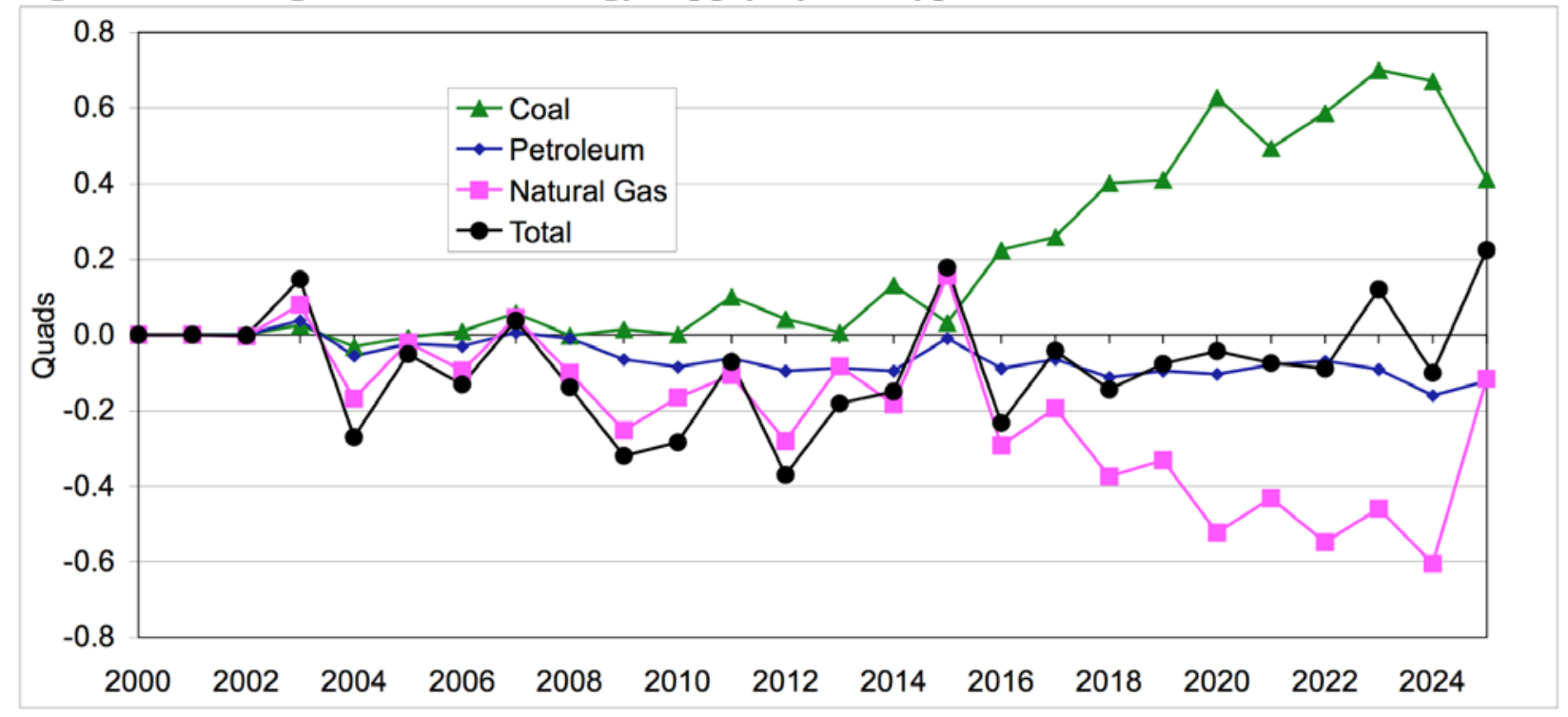

Net total electricity capacity increases by over $40 \mathrm{GW}$ to meet the additional electricity requirements for cooling, with a change in the mix of technologies (Table 9). Most of the increase is in combustion turbines (mainly gas-fired, but some oil), which are quick to build and most useful for meeting peaking needs such as cooling requirements on hot days. Some gas-fired combined cycle, coal plants, renewable resources, and distributed generation are also added. While almost $80 \mathrm{GW}$ of additional capacity is added, $39 \mathrm{GW}$ of capacity are retired. These are mostly older gas or oil steam generators that become uneconomic due to price changes or operating capacity factors.

Table 9. Cumulative changes in electricity capacity by technology by 2025 (GW)

\begin{tabular}{|lrrr|}
\hline & Additions & Retirements & Net \\
\hline \hline Coal Steam & 9.0 & 0.2 & 8.7 \\
Other Fossil Steam & 0.0 & 27.0 & -27.0 \\
Combined Cycle & 5.6 & 0.7 & 4.9 \\
Combustion Turbine/Diesel & 60.5 & 11.1 & 49.4 \\
Nuclear Power & 0.0 & 0.0 & 0.0 \\
Pumped Storage & 0.0 & 0.0 & 0.0 \\
Fuel Cells & 0.0 & 0.0 & 0.0 \\
Renewable Sources & 3.2 & 0.0 & 3.2 \\
Distributed Generation & 1.3 & 0.0 & 1.3 \\
Total & 79.5 & 39.0 & 40.5 \\
\hline
\end{tabular}

These changes may be accentuated by the methodology that DD-NEMS uses to add and retire capacity. It calculates capacity requirements by using a growth rate from the previous three years, but applies that to the most recent demand level. In the case of a high demand year, it will apply the growth rate to this high demand and decide that large amounts of capacity are needed quickly, meaning gas turbines. When demand dips, fewer plants are built and more expensive older plants, most notably gas or oil steam units, are unused and unprofitable for several years, leading to their retirement. This can be seen when comparing 2024 and 2025 results. By 2024, cumulative net additions were $57.8 \mathrm{GW}$, but since 2025 was a cool year in the PCM-IBIS data, 
total capacity did not grow much in that year while for the base case it did. As a consequence, the cumulative net increase by that year was only $40.5 \mathrm{GW}$. To some extent, this methodology actually reflects recent history, with a large expansion in gas turbines and combined cycle, followed by retirements, mothballing, and cancellations.

\subsection{Cost Changes}

As mentioned above, DD-NEMS internally calculates the price for the various energy sources in each region based on input assumptions on supply quantities, technological change, and demand elasticity. Electricity prices are calculated using a wealth of information on existing and new power plant costs and electricity market structure, as well as the prices for different fuel types and contract terms. Figure 19 shows the difference in prices for the key fuels between the reference and varying-temperature case. Note that the electricity price fluctuates more than the others starting in 2007. This is likely due to the higher variability in electrical demand as well as changes in timing and types of power plants added, as described above. At the regional level, the electricity prices fluctuate even more widely, with price differences for some years on the order of $\$ 2 / \mathrm{mmBtu}$ (which translates to $0.7 \phi / \mathrm{kWh}$ ). There is some correlation with changes in regional cooling demands, but other factors influence prices as well.

Figure 19. National energy price differences between the base case and with varying temperatures

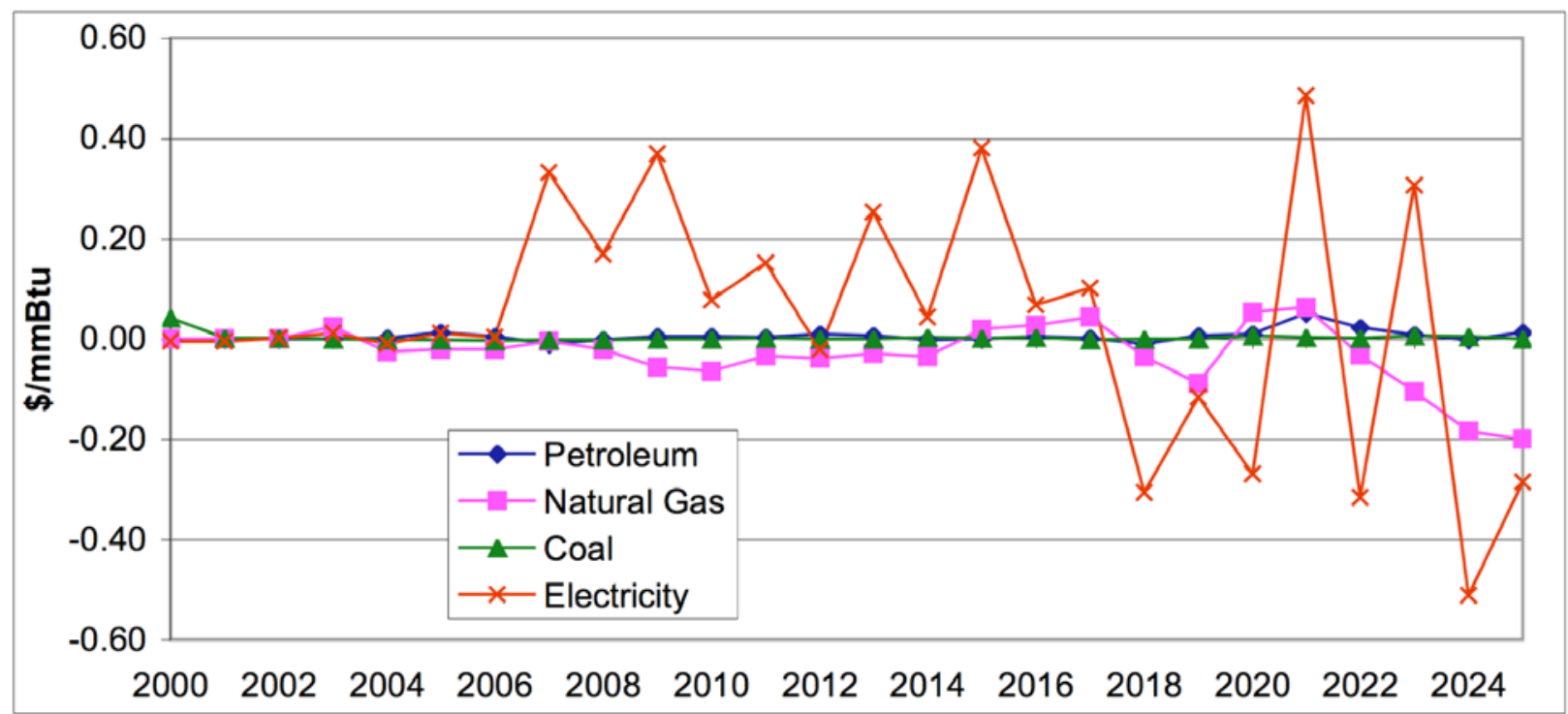

Heating and cooling cost for individual years in each region is tied to energy demand and price. In Table 10, years are grouped into early (pre-2015) and late (2015-2025) periods and the averaged cost differences between the Low- $\Delta \mathrm{T}$ scenario and the reference scenario are compared. In the early period, cost increases are relatively low, or negative (savings), as net energy use is less for the Low- $\Delta \mathrm{T}$ scenario. New England and the E. N. Central regions show savings in the early and late periods. Energy costs are projected to increase (or savings to decrease) in all regions in the late period, especially in the three southeastern regions. 
Table 10. Change in heating and cooling cost for each region (million 2001\$)

\begin{tabular}{|lrr|}
\hline & $2003-2014$ & $2015-2025$ \\
\hline New England & -417 & -274 \\
Mid Atlantic & -1485 & 130 \\
E. N. Central & -3150 & -1191 \\
W. N. Central & -697 & 822 \\
S. Atlantic & 437 & 6489 \\
E. S. Central & -20 & 3196 \\
W. S. Central & 716 & 3886 \\
Mountain & 186 & 643 \\
Pacific & 1547 & 3938 \\
\hline National & -2883 & 17641 \\
\hline
\end{tabular}

Finally, while heating and cooling energy use may have significant changes due to the fluctuations in temperature (from $-6 \%$ to $+8 \%$ of heating and cooling energy as shown in Figure 14, Figure 15, and Figure 16), price changes will further modify the impacts on consumer bills. Figure 20 shows the heating and cooling cost changes when the same prices are applied to both cases and when the prices from each scenario are applied to each respective case. Applying the new prices to the energy used for all purposes (including non-heating and cooling) shows the role that other energy uses have in the over-all cost changes. Even though energy use for other sectors changed relatively little compared to heating and cooling (Figure 17), applying the regional price and demand changes results in much larger swings in total cost. These changes are most driven by the fluctuations in electricity prices, as well as the drop in natural gas prices in the last years of the study. Since DD-NEMS calculates these prices internally, it may be necessary to explore the algorithms used as regards to their response to temperature-induced demand changes.

Figure 20. National cost changes for heat and cooling end-use and for all energy use

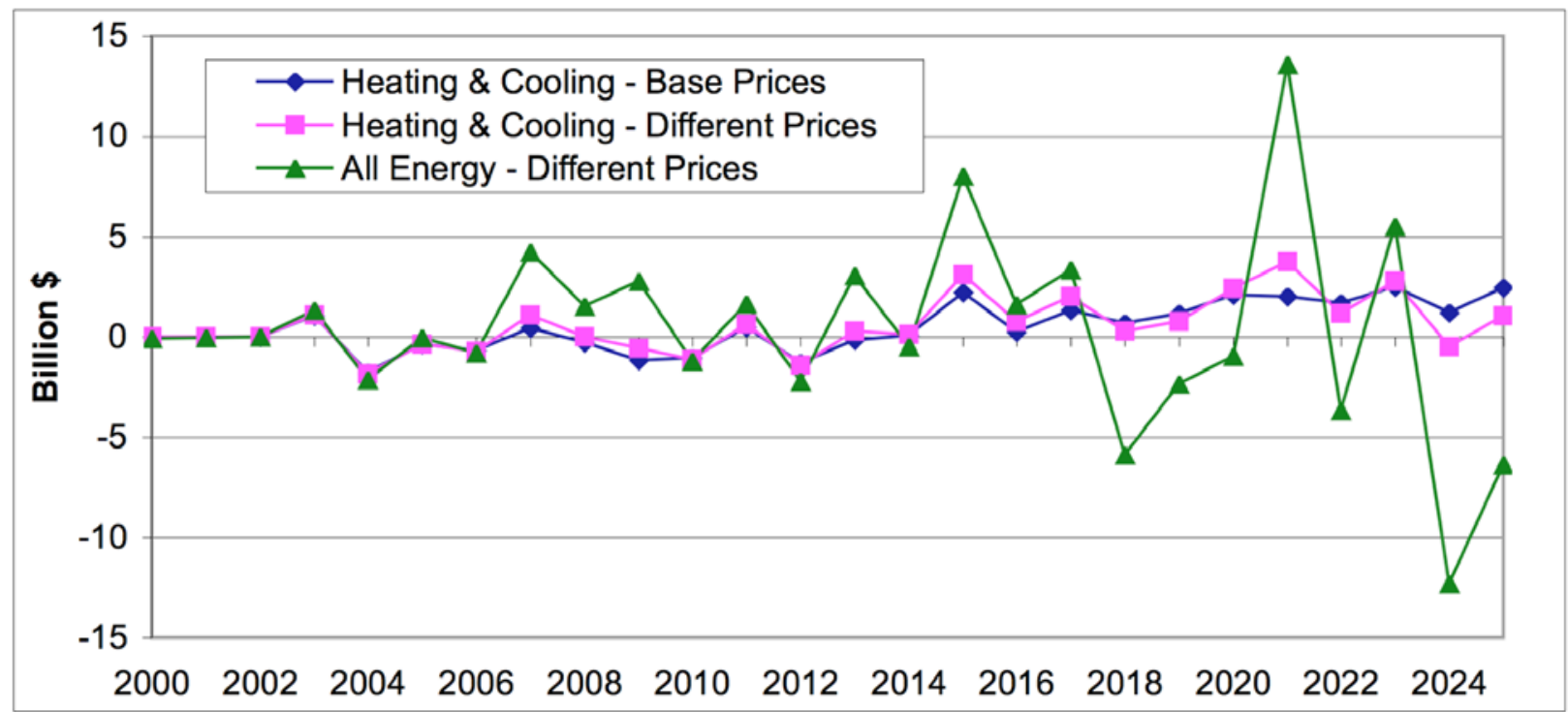

\subsection{Carbon Changes}

Lastly, with a change in energy use, both in type and quantity, the amount of carbon emissions will change. This change provides a small amount of feedback to global climate change. In the 
scenario examined, coal consumption increased and natural gas consumption decreased (Figure 18). Since coal is more carbon-intensive, the net impact was a small increase in carbon emissions (Figure 21) in the later years. The peak increase in 2023 of 9.4 million tonnes carbon represents $0.43 \%$ of total U.S. emissions for that year. Further, the trend shows a continuing increase in carbon emissions so the result of climate change could be a slight positive feedback in the postulated set of circumstances.

Figure 21. Carbon emission changes in the Low $\Delta T$ Scenarios

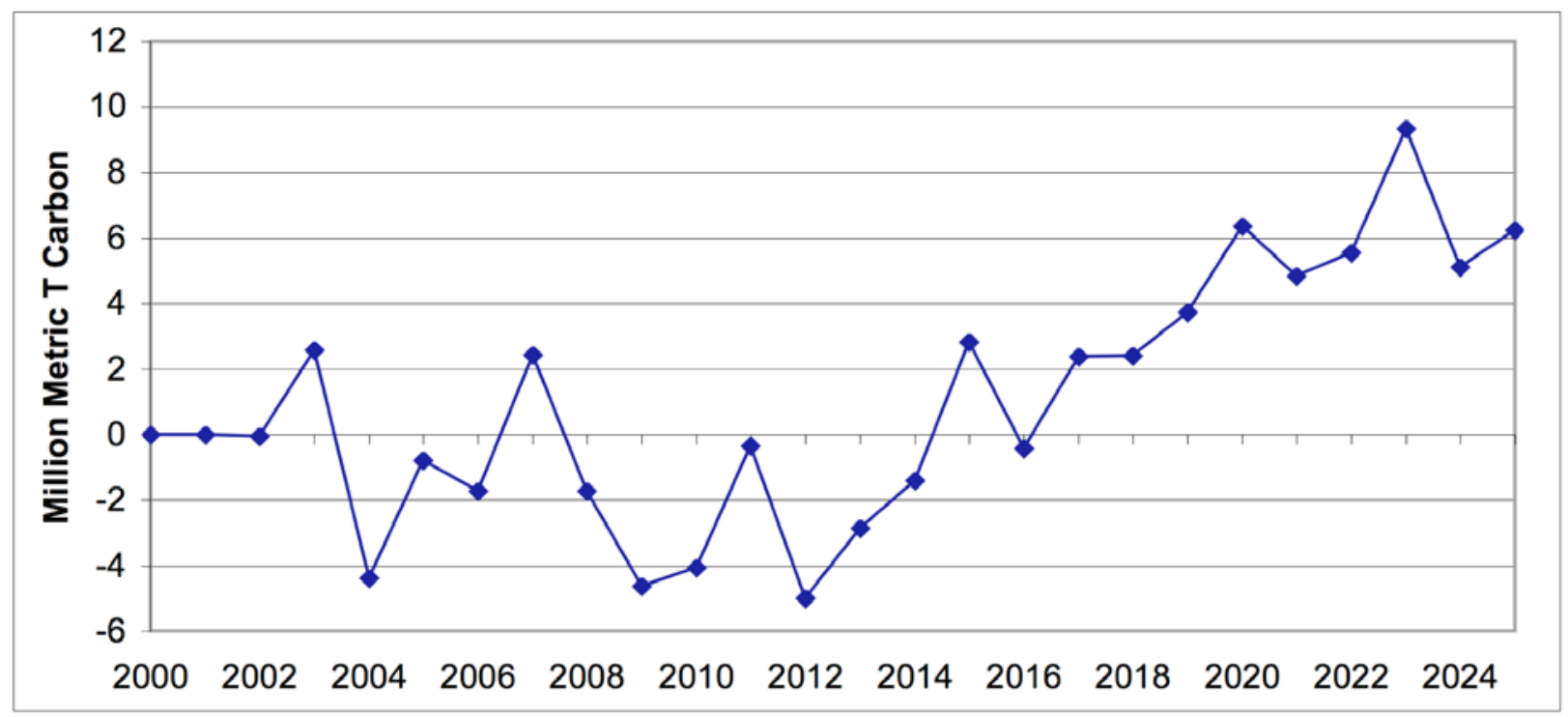




\section{High $\Delta \mathrm{T}$ Versus Low $\Delta \mathrm{T}$ Results}

\subsection{Temperature Differences}

In the High- $\Delta \mathrm{T}$ scenario, temperatures during the study period averaged $1.3^{\circ} \mathrm{F}$ higher than the Low- $\Delta \mathrm{T}$ scenario. However, these temperature increases were more pronounced in the winter months (October-March) at $1.5^{\circ} \mathrm{F}$, versus $1.1^{\circ} \mathrm{F}$ in the summer months. Each region except the Pacific showed a similar response (Figure 22). As a consequence, the average number of HDD decreased by 309 degree-days while the average increase in CDD was only 160 degree-days, as compared to the Low- $\Delta \mathrm{T}$ scenario. This means that with higher temperature sensitivity to $\mathrm{CO}_{2}$, the heating needs declined more than cooling needs increased. Table 11 shows the average change in HDD and CDD during the 2003-2025 period versus the 1971-2000 averages from NCDC.

Figure 22. Average temperature increase for 2003-2025 in the High- $\Delta \mathrm{T}$ versus the Low- $\Delta \mathrm{T}$ scenarios by region

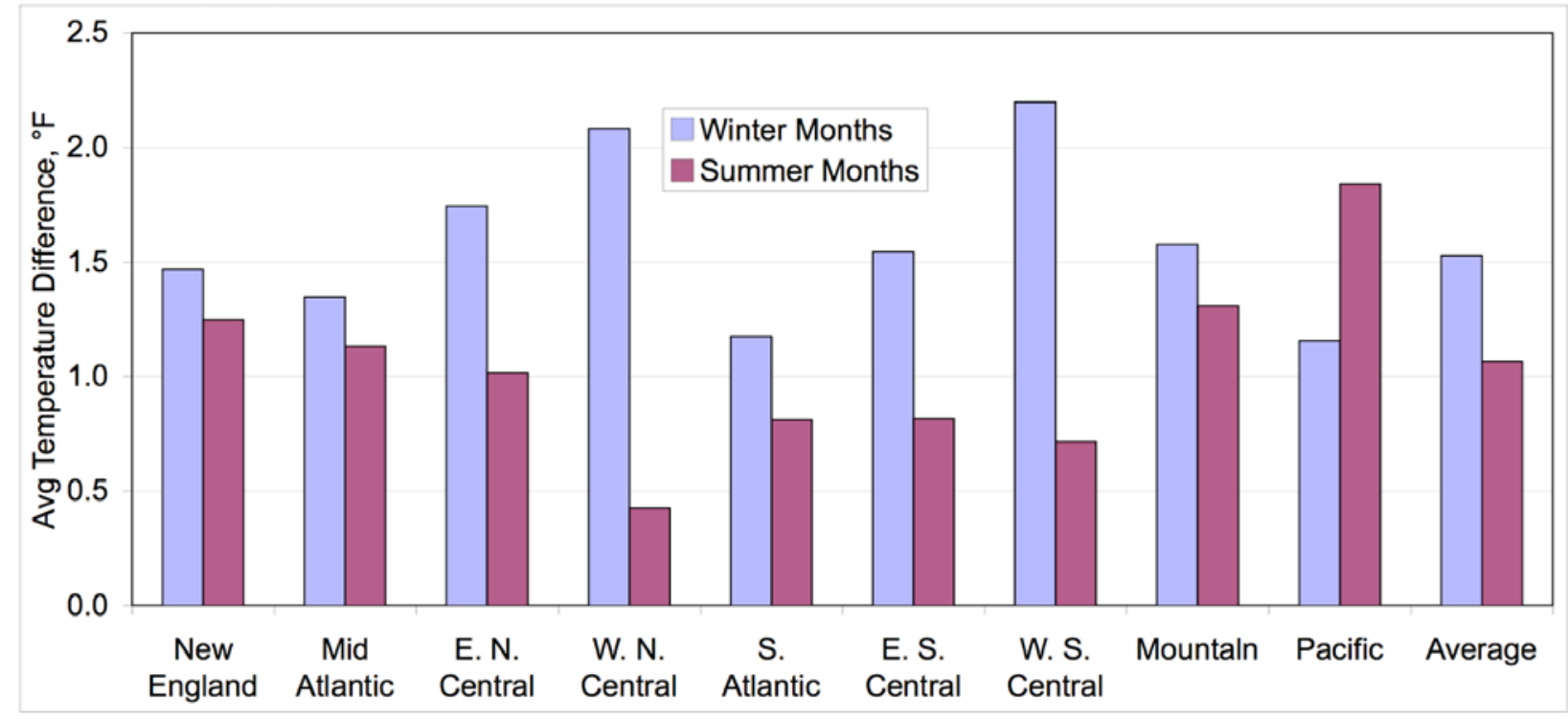

Table 11. Reference scenario degree-days (1971-2000 averages) and average change in 2003-2025 from Reference scenario for $L o w-\Delta T$ and High- $\Delta T$ scenarios

\begin{tabular}{|c|c|c|c|c|c|c|c|c|c|c|}
\hline Scenario & $\begin{array}{c}\text { New } \\
\text { England } \\
\end{array}$ & $\begin{array}{c}\text { Mid } \\
\text { Atlantic }\end{array}$ & $\begin{array}{l}\text { E. N. } \\
\text { Central }\end{array}$ & $\begin{array}{l}\text { W. N. } \\
\text { Central }\end{array}$ & $\begin{array}{c}\mathrm{S} . \\
\text { Atlantic } \\
\end{array}$ & $\begin{array}{l}\text { E. S. } \\
\text { Central }\end{array}$ & $\begin{array}{l}\text { W. S. } \\
\text { Central }\end{array}$ & Mountain & Pacific & Average \\
\hline \multicolumn{11}{|l|}{ 1971-2000 Avg. } \\
\hline HDD & 6612 & 5910 & 6498 & 6750 & 2853 & 3603 & 2286 & 5209 & 3226 & 4523 \\
\hline CDD & 418 & 655 & 708 & 928 & 1964 & 1549 & 2448 & 1244 & 704 & 1215 \\
\hline \multicolumn{11}{|l|}{$\begin{array}{l}\text { Low- } \Delta \mathrm{T} \text { change } \\
\text { from Reference }\end{array}$} \\
\hline HDD & -189 & -190 & -290 & -156 & -127 & -133 & -31 & -104 & -93 & -150 \\
\hline CDD & 79 & 98 & 102 & 84 & 187 & 186 & 202 & 115 & 107 & 133 \\
\hline \multicolumn{11}{|l|}{$\begin{array}{l}\text { High- } \Delta \mathrm{T} \text { change } \\
\text { from Reference }\end{array}$} \\
\hline HDD & -575 & -517 & -684 & -572 & -278 & -381 & -317 & -465 & -432 & -459 \\
\hline CDD & 180 & 215 & 202 & 115 & 396 & 364 & 442 & 279 & 317 & 292 \\
\hline
\end{tabular}




\subsection{Regional Energy Use Changes}

Each region will have different changes in their heating and cooling depending on the amount of heating and cooling degree-days as compared to the long-run average used in the Reference case. In general, the more northern regions of the country have a larger decrease in end-use heating needs than an increase in their cooling needs. Figure 11 and Figure 12 show the end-use and primary heating and cooling for the Low- $\Delta \mathrm{T}$ scenario. Figure 23 combines the results for the High- $\Delta \mathrm{T}$ scenario to show the changes in end-use energy and primary energy. All of the regions show a net reduction in end-use energy over the study period. When an adjustment for primary energy is added to each region, the net change in primary energy is positive for the southern and western regions but not for the north and northeastern regions.

Figure 23. Cumulative change (2003-2025) in end-use and primary heating and cooling energy between the High- $\Delta \mathrm{T}$ scenario and the Reference scenario.

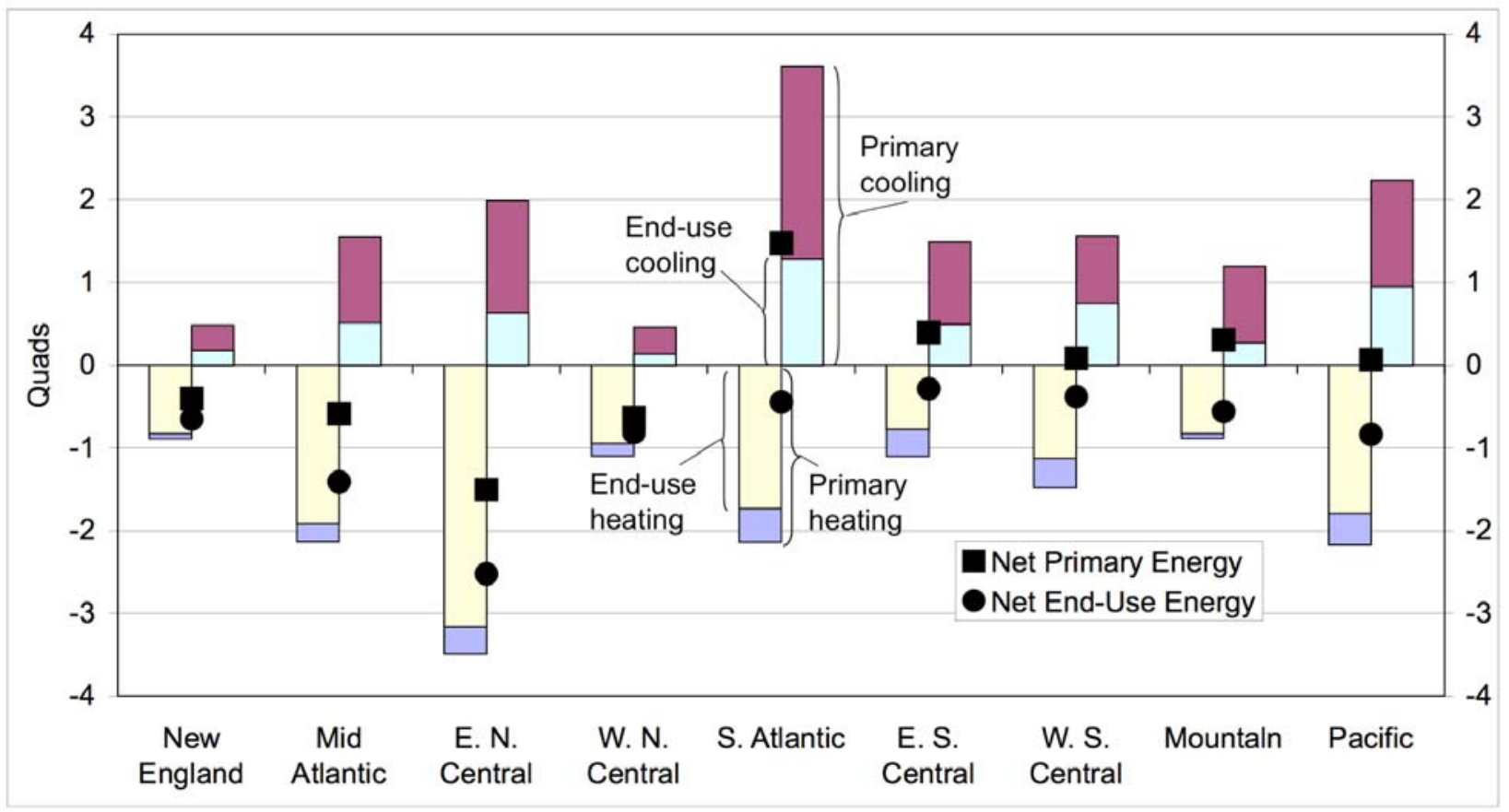

\subsection{Heating and Cooling Differences}

The primary energy use in the High- $\Delta \mathrm{T}$ scenario shows an increase in both the cooling and decrease in the heating energy use compared to the Low- $\Delta \mathrm{T}$ scenario, as expected (Figure 24). While the heating energy in Low- $\Delta \mathrm{T}$ scenario is relatively constant in the latter years, in the High- $\Delta \mathrm{T}$ scenario the heating energy use continues to decline. As a consequence, and because the heating and cooling cancel each other, the net energy use is actually somewhat below the net energy use in the Low- $\Delta \mathrm{T}$ scenario in many of the years. The sum of the net energy use for heating and cooling over the full study period in the High- $\Delta \mathrm{T}$ scenario was even below the Reference scenario (Table 12). While the change in net energy for the Low- $\Delta \mathrm{T}$ scenario totaled 1.09 Quads, for the High- $\Delta \mathrm{T}$ scenario the net was -0.82 Quads. Regionally, only the S. Atlantic and S.E. Central had an increase in net energy requirements with the higher temperature responsiveness. 
Figure 24. Primary energy change from Reference for heating and cooling in each scenario

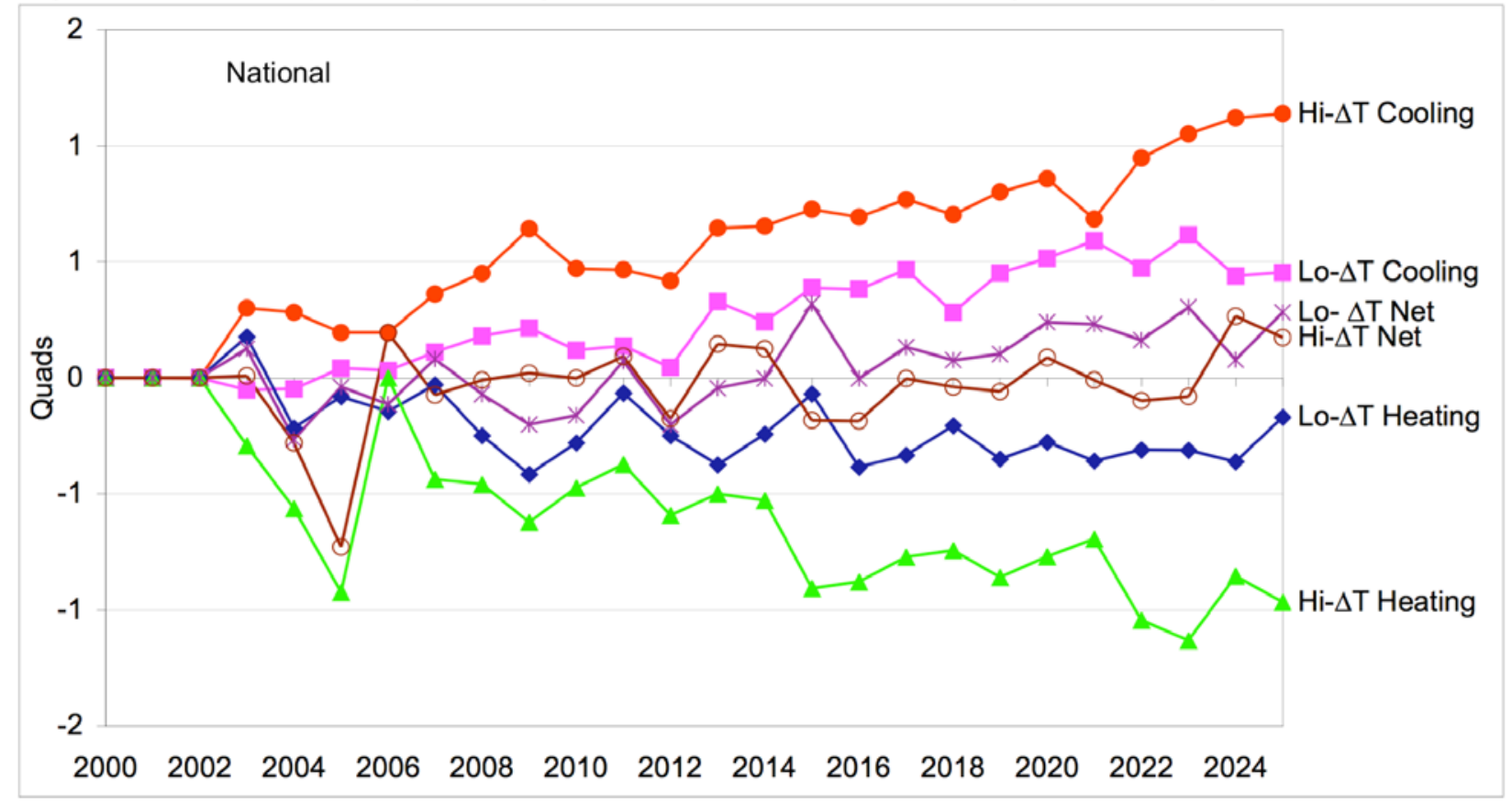

Table 12. Total primary energy increases (decreases) for heating, cooling, and net energy between the two varying temperature scenarios and the Reference scenario. (Quads)

\begin{tabular}{|c|c|c|c|c|c|c|c|c|c|c|}
\hline Scenario & $\begin{array}{c}\text { New } \\
\text { England }\end{array}$ & $\begin{array}{c}\text { Mid } \\
\text { Atlantic }\end{array}$ & $\begin{array}{c}\text { E. N. } \\
\text { Central }\end{array}$ & $\begin{array}{l}\text { W. N. } \\
\text { Central }\end{array}$ & $\begin{array}{c}\mathrm{S} . \\
\text { Atlantic }\end{array}$ & $\begin{array}{c}\text { E. S. } \\
\text { Central }\end{array}$ & $\begin{array}{l}\text { W. S. } \\
\text { Central }\end{array}$ & Mountain & Pacific & $\begin{array}{c}\text { National } \\
\text { Total }\end{array}$ \\
\hline \multicolumn{11}{|l|}{ Low- $\Delta \mathrm{T}$} \\
\hline Heating & -0.27 & -0.83 & -1.56 & -0.29 & -1.13 & -0.48 & -0.18 & -0.14 & -0.43 & -5.30 \\
\hline Cooling & 0.18 & 0.66 & 0.94 & 0.33 & 1.68 & 0.74 & 0.67 & 0.49 & 0.71 & 6.40 \\
\hline Net Energy & -0.09 & -0.17 & -0.62 & 0.04 & 0.55 & 0.25 & 0.49 & 0.35 & 0.29 & 1.09 \\
\hline \multicolumn{11}{|l|}{ High- $\Delta \mathrm{T}$} \\
\hline Heating & -0.89 & -2.14 & -3.49 & -1.10 & -2.14 & -1.10 & -1.48 & -0.88 & -2.17 & -15.39 \\
\hline Cooling & 0.48 & 1.55 & 1.99 & 0.46 & 3.61 & 1.49 & 1.56 & 1.19 & 2.24 & 14.57 \\
\hline Net Energy & -0.40 & -0.59 & -1.51 & -0.64 & 1.47 & 0.39 & 0.08 & 0.31 & 0.06 & -0.82 \\
\hline
\end{tabular}

These results exemplify the danger in assuming that increased temperatures will raise energy needs, and higher temperature responsiveness will lead to higher energy use. If the temperature increases are largely in winter-time then energy use decreases. At a more fine-grained level, temperature increases at night-time may also influence the relative amount of heating versus cooling required. However, this latter phenomenon was not analyzed in our research.

While all regions are affected by heating needs reductions, those regions that most use space cooling will be most sensitive to the rise in cooling needs. Showing the net change in primary energy for heating and cooling as a percentage of the primary energy used for heating and cooling in the base case reveals the relative impact of the energy change on the region's total energy use for this purpose. Figure 25 shows the relative percentage of change in primary energy for the two North Central regions (E.N. Central W.N. Central) and the three Southern regions (E. S. Central, W. S. Central, and S. Atlantic) combined. The southern region has consistent results in both the High $-\Delta \mathrm{T}$ and Low- $\Delta \mathrm{T}$ scenarios: initial decline from the Reference scenario and a gradual increase over time to approximately $4 \%$ increase in net energy use. The north-central 
region, though, shows dramatically lower net energy use in the High- $\Delta \mathrm{T}$ scenario since reductions in heating needs outweigh the increase in cooling.

Figure 25. Change in net primary energy use as \% of total heating and cooling energy for North Central regions (East and West) and South regions (West, East, and Atlantic)

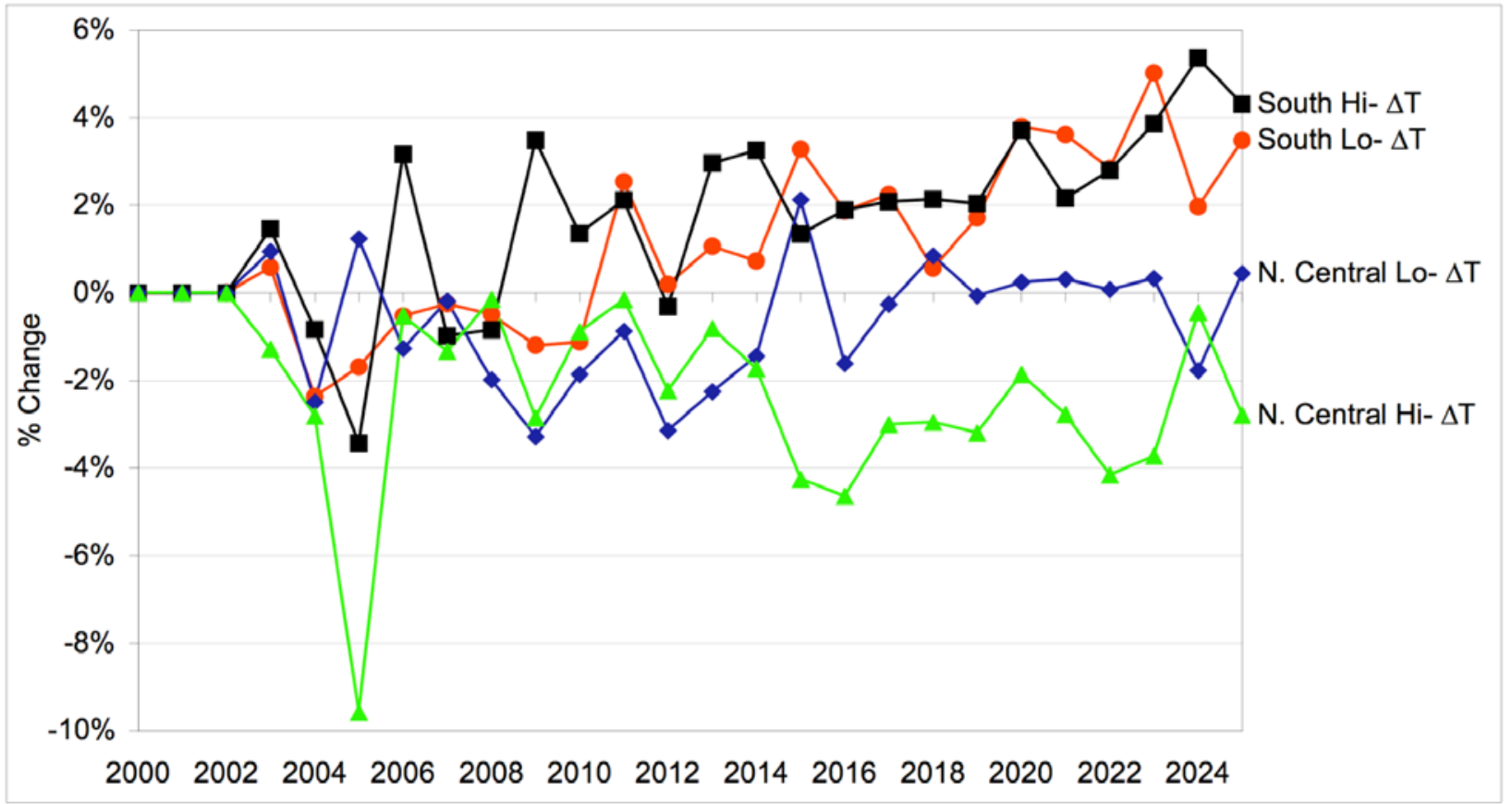

\subsection{Other Demand Sectors}

Because of the changes in energy use for heating and cooling, the supplies and prices for other energy uses will also change, which can in turn change the energy demands for uses other than heating or cooling. These will generally be secondary to the change in heating and cooling, but since these latter two are opposite and so cancel each other out, the other uses become significant contributions to the change in total energy use (Figure 26, Figure 27, and Table 13). (Figure 17 shows the same data as Figure 26, but with further separation of the other categories.) The Low$\Delta \mathrm{T}$ scenario has the heating reduction somewhat level out, but the High- $\Delta \mathrm{T}$ scenario has the heating use continue to decline in the latter years. 
Figure 26. Change in national primary energy use for heating, cooling, other sectors, and total for the Low- $\Delta \mathrm{T}$ scenario

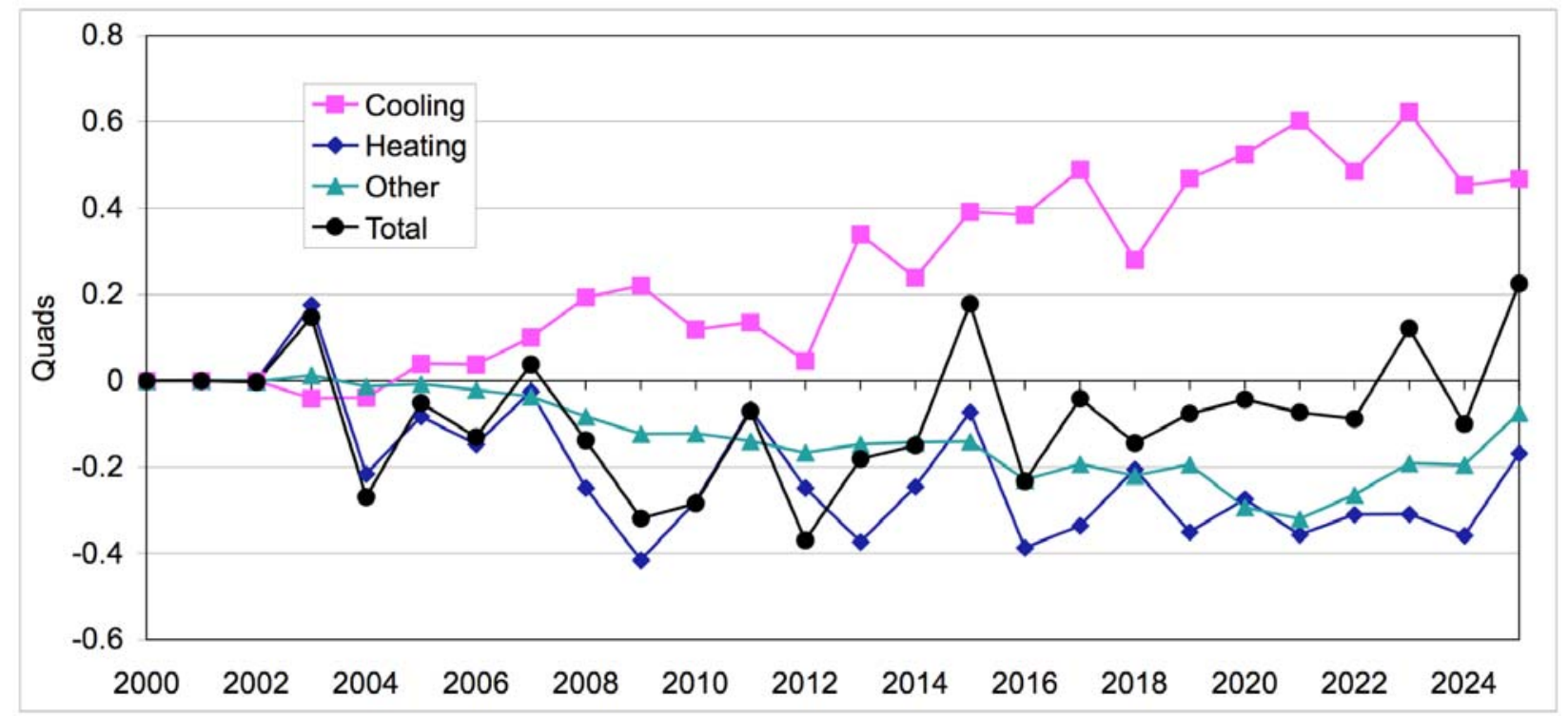

Figure 27. Change in national primary energy use for heating, cooling, other sectors, and total for the High- $\Delta \mathrm{T}$ scenario

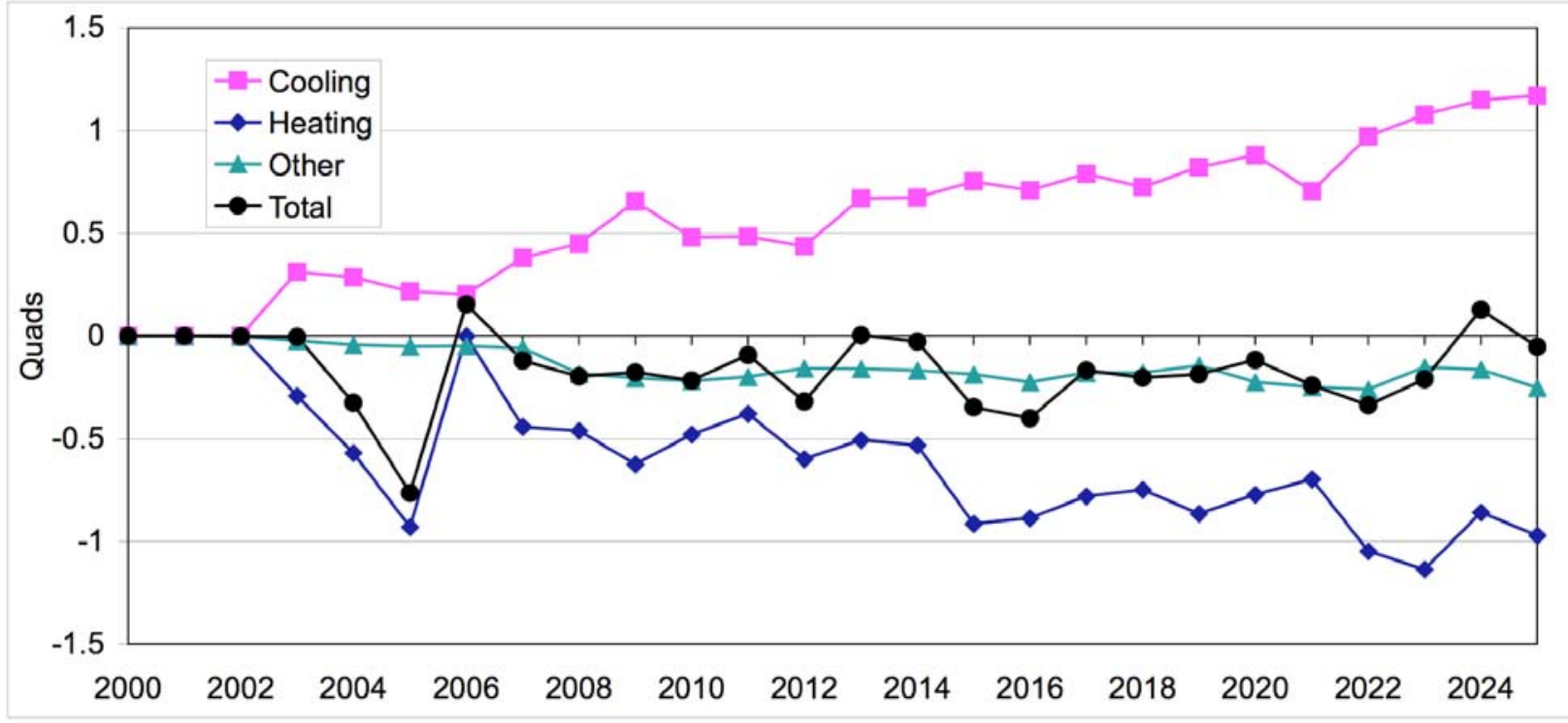

Table 13. Cumulative energy change by sector (Quads)

\begin{tabular}{|l|cc|}
\hline & Low- $\Delta \mathrm{T}$ & High- $\Delta \mathrm{T}$ \\
\hline \hline Heating & -5.30 & -15.49 \\
Cooling & 6.55 & 15.01 \\
Other Residential & -1.03 & -1.13 \\
Other Commercial & -1.10 & -1.29 \\
Industrial & -1.03 & -1.04 \\
Transportation & -0.15 & -0.27 \\
\cline { 2 - 3 } Total & -2.06 & -4.22 \\
\hline
\end{tabular}




\subsection{Changes by Fuel Type}

Because DD-NEMS is a fully integrated model, the supplies and price changes flow to all sectors. Energy reductions in the other sectors, when combined, serve to moderate the net energy increase from space conditioning in the residential and commercial sectors. In the High- $\Delta \mathrm{T}$ scenario, the heating and cooling amounts increase in dominance but being opposite, the net amount is negative. This causes the reduction in energy in the other sectors to become even more significant (Table 13).

The High- $\Delta \mathrm{T}$ scenario has higher levels of increase or decrease in coal and natural gas use as compared to the Low- $\Delta \mathrm{T}$ scenario (Table 14). Much of the increase in coal use occurred in the 2010-2020 time frame (Figure 28 versus Figure 18). Because natural gas is used both directly in heating and as a major contributor to electricity production used for cooling, there is not as large a change in the coal and gas use as there was in the heating and cooling use (Table 13). Petroleum use declines more in the High- $\Delta \mathrm{T}$ scenario because it is more directly used for heating than cooling.

Table 14. Cumulative energy change by fuel (Quads)

\begin{tabular}{|l|rr|}
\hline & Low- $\Delta \mathrm{T}$ & High- $\Delta \mathrm{T}$ \\
\hline Petroleum & -1.57 & -2.76 \\
Natural Gas & -5.05 & -7.80 \\
Coal & 5.17 & 7.09 \\
Other & -0.62 & -0.75 \\
\cline { 2 - 3 } Total & -2.06 & -4.22 \\
\hline
\end{tabular}

Figure 28. Change in national energy supply by fuel type the High- $\Delta T$ scenario

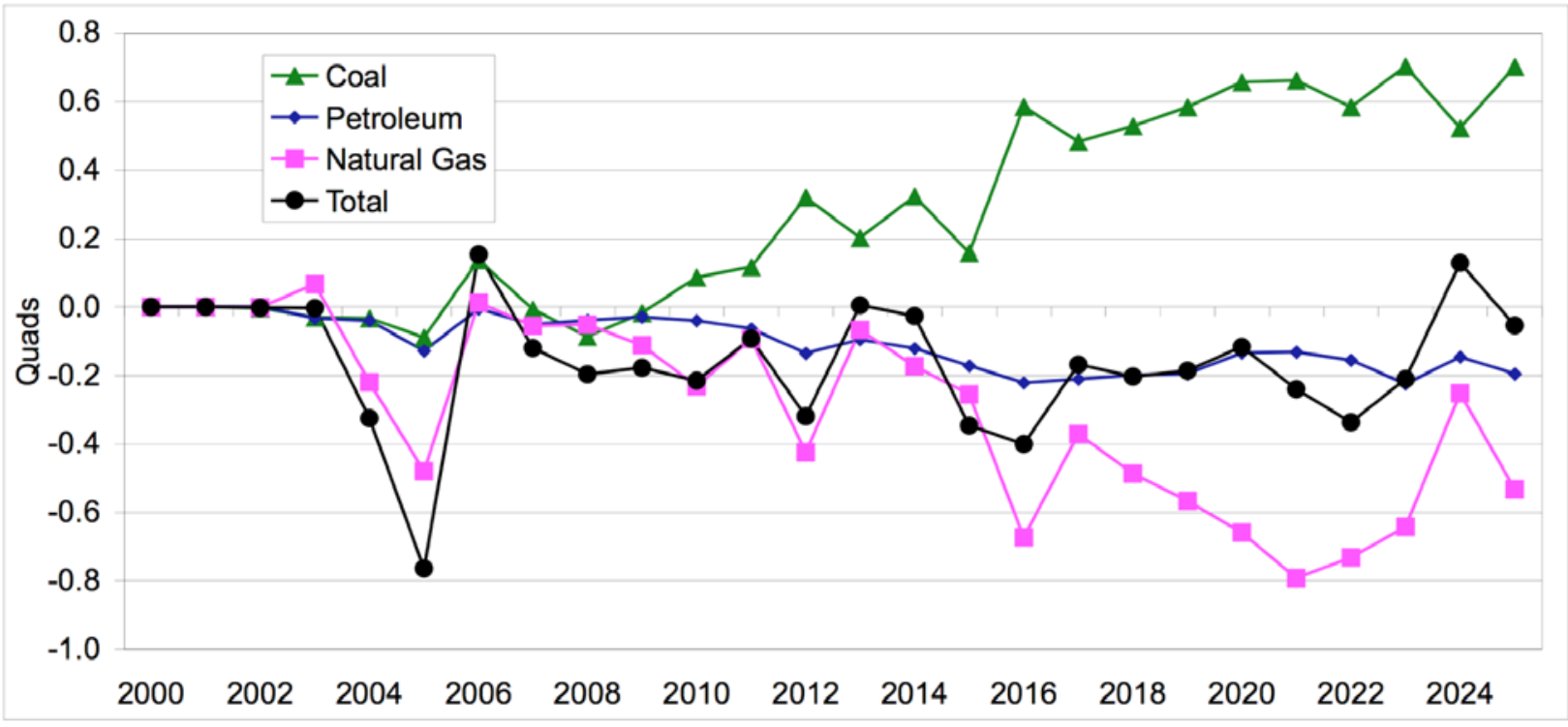

Net total electricity capacity increased by $40 \mathrm{GW}$ in the Low- $\Delta \mathrm{T}$ and $80 \mathrm{GW}$ in the High- $\Delta \mathrm{T}$ scenario to meet the additional electricity requirements for cooling, with a change in the mix of technologies (Table 15). Most of the increase is in oil- and gas-fired combustion turbines, which are quick to build and most useful for meeting peaking needs such as cooling requirements on 
hot days. Some gas-fired combined cycle, coal plants, renewable resources, and distributed generation are also added. In the Low- $\Delta \mathrm{T}$ scenario, while almost $80 \mathrm{GW}$ of additional capacity are added, $39 \mathrm{GW}$ of capacity are retired. These are mostly older gas or oil steam generators that become uneconomic due to price changes or operating capacity factors. Since these plants are typically only used for peaking and emergency needs, if demand dips following construction of new plants because of volatility in cooling demand, these plants are not called on and are retired within DD-NEMS. To some extent, this methodology actually reflects recent history, with a large expansion in gas turbines and combined cycle, followed by recent retirements, mothballing, and cancellations.

Table 15. Cumulative changes in electricity capacity by technology by 2025 (GW)

\begin{tabular}{|l|rrr|rrr|}
\hline & \multicolumn{3}{|c|}{ Low- $\Delta$ T Scenario } & \multicolumn{3}{c|}{ High- $\Delta$ T Scenario } \\
\hline & Additions & Retirements & \multicolumn{1}{c|}{ Net } & Additions & Retirements & Net \\
\hline Coal Steam & 9.0 & 0.2 & 8.7 & 17.0 & 1.1 & 15.9 \\
Other Fossil Steam & 0.0 & 27.0 & -27.0 & 0.0 & -1.7 & 1.7 \\
Combined Cycle & 5.6 & 0.7 & 4.9 & 10.5 & 0.5 & 10.0 \\
Combustion Turbine/Diesel & 60.5 & 11.1 & 49.4 & 51.6 & 2.6 & 49.0 \\
Nuclear Power & 0.0 & 0.0 & 0.0 & 0.0 & 0.0 & 0.0 \\
Pumped Storage & 0.0 & 0.0 & 0.0 & 0.0 & 0.0 & 0.0 \\
Fuel Cells & 0.0 & 0.0 & 0.0 & 0.0 & 0.0 & 0.0 \\
Renewable Sources & 3.2 & 0.0 & 3.2 & 2.0 & 0.0 & 2.0 \\
Distributed Generation & 1.3 & 0.0 & 1.3 & 0.9 & 0.0 & 0.9 \\
Total & 79.5 & 39.0 & 40.5 & 81.9 & 2.4 & 79.5 \\
\cline { 2 - 7 }
\end{tabular}

\subsection{Cost Changes}

As mentioned above, DD-NEMS internally calculates the price for the various energy sources in each region based on input assumptions on supply quantities, technological change, and demand elasticity. Electricity prices are calculated using a wealth of information on existing and new power plant costs and electricity market structure, as well as the prices for different fuel types and contract terms. Figure 29 shows the difference in prices for the key fuels between the reference and High- $\Delta$ T case. Note that starting in 2008 the electricity price fluctuates more than the others. (A price of $0.8 \$ / \mathrm{mmBtu}$ equals about $0.3 \phi / \mathrm{kWh}$.) This is likely due to the higher variability in electrical demand as well as changes in timing and types of power plants added, as described above. 
Figure 29. Average fuel price changes between the High- $\Delta T$ and Reference scenarios.

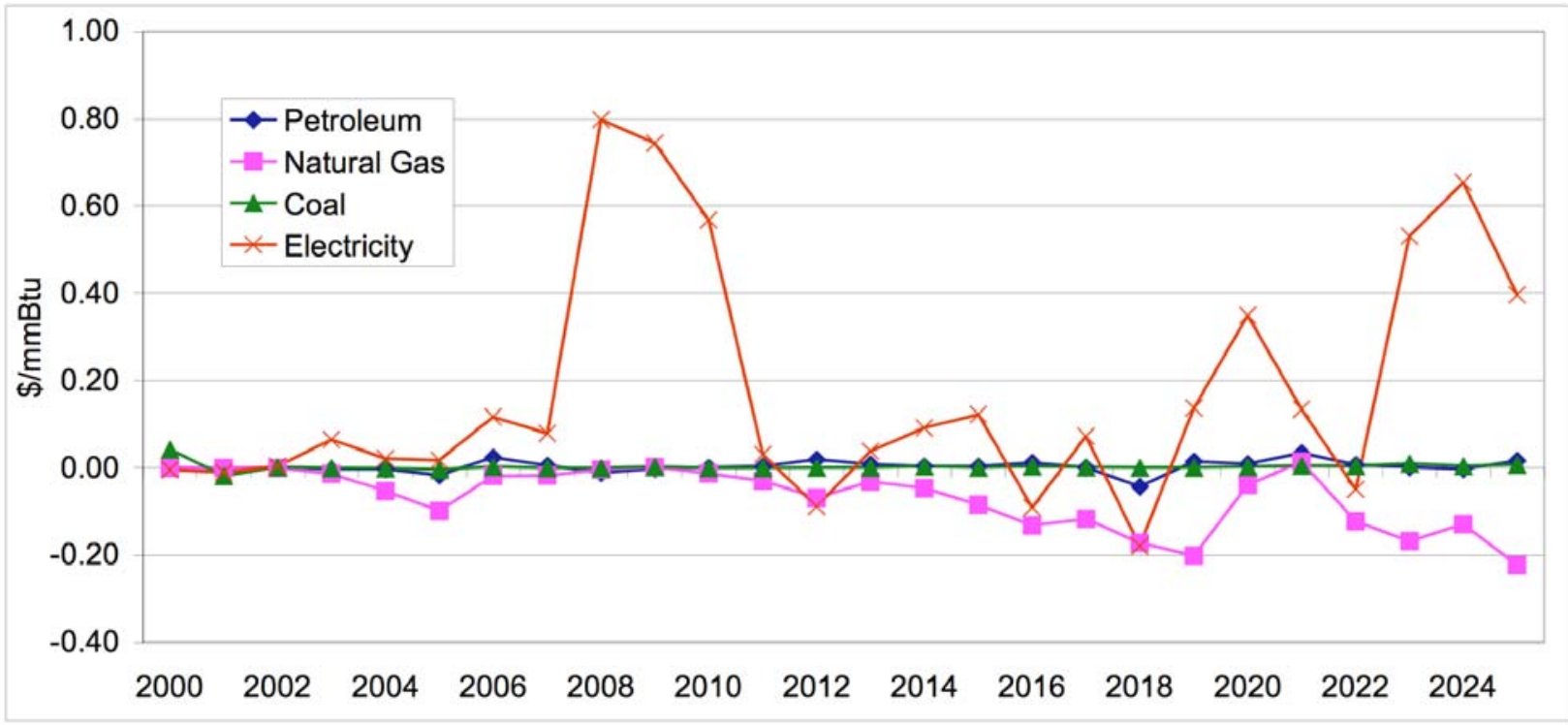

The cost for heating and cooling in each region is tied to the energy and price changes over time. In the early years, 2003-2015, the cost for most regions is generally low or negative compared to the reference case since net energy use is less. In the later years though, energy costs are higher, especially for the southern and Pacific regions (Table 16). Under the Low- $\Delta$ T scenario, the New England and the E. N. Central regions have savings in both periods, while in the High- $\Delta \mathrm{T}$ scenario, costs are lower in both periods for all of the northern regions. Considering the entire study period, costs are dramatically different between the four northern and the southern and Pacific regions, while the Mountain region, which includes both northern and southern states, sees little change (Figure 30).

Table 16. Change in heating and cooling cost for each region (\$Billion)

\begin{tabular}{|l|ccc|ccc|}
\hline & \multicolumn{3}{|c|}{ Low- $\Delta$ T Scenario } & \multicolumn{3}{c|}{ High- $\Delta$ T Scenario } \\
& $2003-2014$ & $2015-2025$ & $2003-2025$ & $2003-2014$ & $2015-2025$ & $2003-2025$ \\
\hline New England & -0.4 & -0.3 & -0.7 & -0.8 & -1.9 & -2.7 \\
Mid Atlantic & -1.5 & 0.1 & -1.4 & -0.9 & -3.3 & -4.2 \\
E. N. Central & -3.2 & -1.2 & -4.3 & -4.2 & -6.5 & -10.7 \\
W. N. Central & -0.7 & 0.8 & 0.1 & -1.9 & -2.4 & -4.3 \\
S. Atlantic & 0.4 & 6.5 & 6.9 & 4.3 & 9.5 & 13.8 \\
E. S. Central & 0.0 & 3.2 & 3.2 & 1.1 & 2.8 & 3.9 \\
W. S. Central & 0.7 & 3.9 & 4.6 & 0.6 & 2.3 & 2.9 \\
Mountain & 0.2 & 0.6 & 0.8 & -0.5 & -0.1 & -0.6 \\
Pacific & 1.5 & 3.9 & 5.5 & 1.8 & 6.1 & 8.0 \\
\hline National & -2.9 & 17.6 & 14.8 & -0.4 & 6.5 & 6.1 \\
\hline
\end{tabular}


Figure 30. Cumulative heating and cooling cost difference from Reference scenario for each region

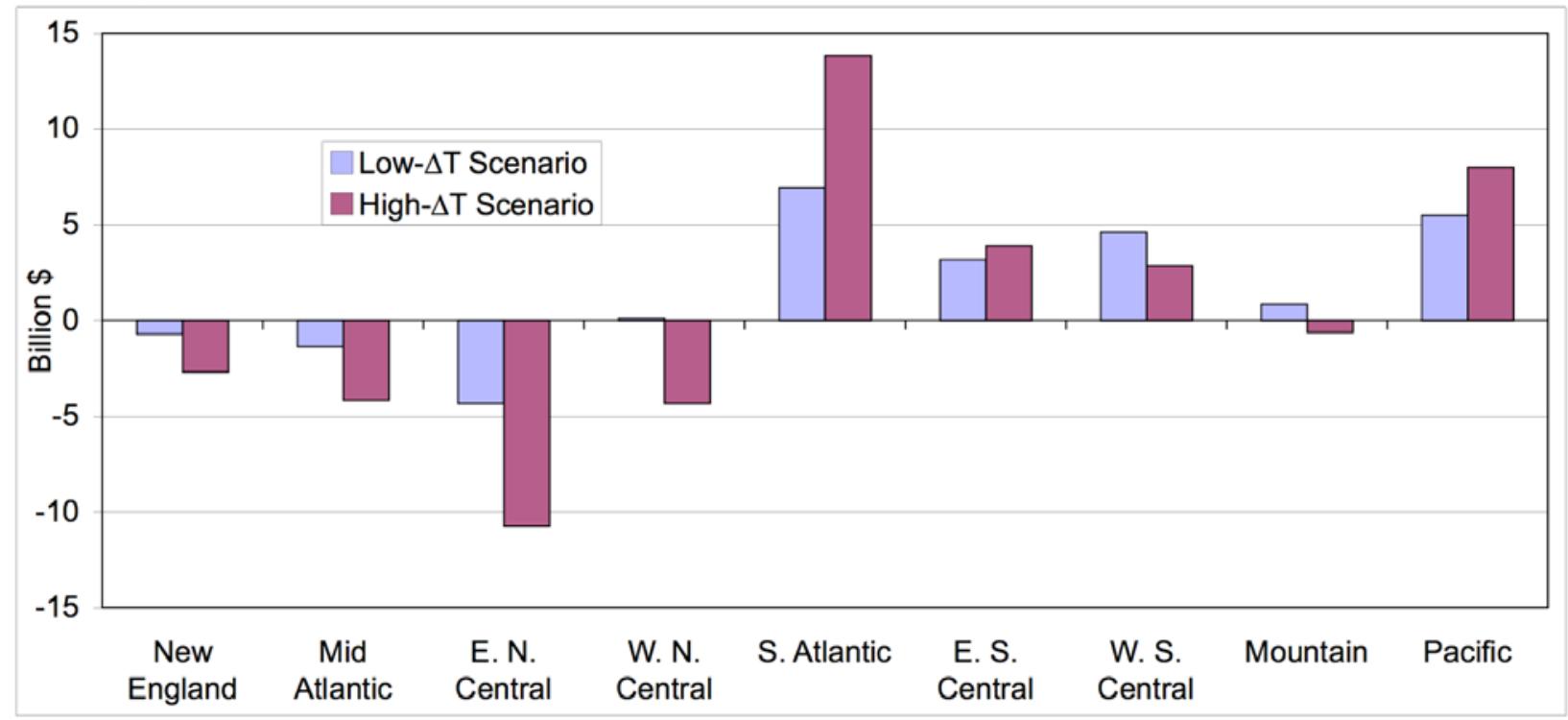

Nationally, the costs in the Low $-\Delta \mathrm{T}$ scenario changed from $-\$ 2.9$ billion in the early years to $+\$ 17.6$ billion in the later years as cooling needs increased. However, the High- $\Delta \mathrm{T}$ scenario showed less cost changes in either period: from $-\$ 0.4$ billion to $+\$ 6.5$ billion. The changes in energy costs could have a broader impact on the economy of the country, but the changes are miniscule to the overall GDP and this analysis did not include the macro-economic modeling used by the full NEMS program.

\subsection{Carbon Changes}

The changes in energy use in the country will change the amount of $\mathrm{CO}_{2}$ released into the atmosphere. In the Low- $\Delta \mathrm{T}$ scenario, total energy increased in the latter years so an increase in $\mathrm{CO}_{2}$ occurred as expected (Figure 31). What is interesting is that in the High- $\Delta \mathrm{T}$ scenario, the $\mathrm{CO}_{2}$ increased as well, even though total energy use was less than in the reference scenario for most of the years (Figure 28). Carbon-intensive coal use increased while other fuels declined, so the net carbon emissions increased despite the reduction in energy use. The peak increase in 2023 of 9.4 million tonnes carbon represents $0.43 \%$ of total U.S. emissions for that year. Further, the trend shows a continuing increase in carbon emissions so the result of climate change could be a slight positive feedback in the postulated set of circumstances. 
Figure 31. Carbon emission changes from Reference scenario

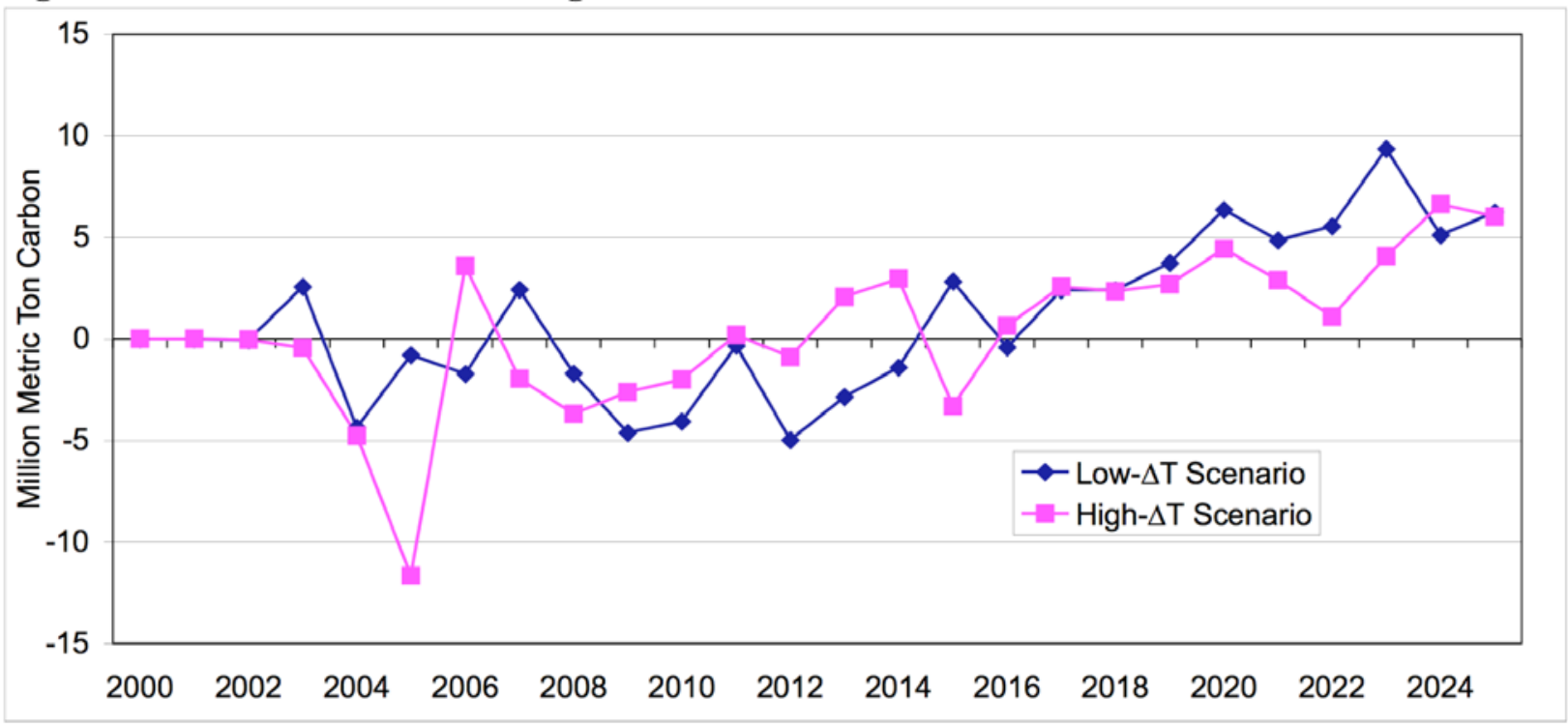




\section{Conclusions}

The analysis conducted so far provides interesting insights into the interplay between climate change, energy use, and economics. While cooling needs increase energy use, heating needs reduce the amount. Since cooling (using electricity) is more inefficient than heating, the increase in primary energy use is amplified. While a modest temperature sensitivity to $\mathrm{CO}_{2}$ results in increases in net energy use, a higher temperature sensitivity actually reduces energy use nationally. Reductions in heating needs because of temperature increases in the winter months (especially in the northern regions) were more than the increased cooling needs. The variety of energy sources used for these services, the regional variation in energy requirements, and the market impacts on other energy consumption all combine to complicate the calculation of the net impact on the U.S. A slight trend in latter years of increased net energy use, cost, and carbon emissions occurred. Other economic changes such as prices may mitigate the increase, but with concomitant change to economic growth. Regional analysis shows a much larger impact in the southern regions of the U.S., while some northern regions have energy and cost savings over the whole span of time studied.

Relative carbon emissions rose for all scenarios studied as coal-based electricity for cooling needs grew, as compared to the reference scenario (Figure 32). The scenario with a gradual $1^{\circ} \mathrm{F}$ rise by 2025 had the lowest impact, but the others had similar trends. In all cases, there was an initial decline as heating reductions outpaced cooling increases, but with additional temperature increases, the cooling-related increases overwhelmed the other impacts and carbon emissions rose. While the amounts in any year are small, the trend indicates that there would be a continued build-up with increasing warmth.

Figure 32. Carbon emission changes from reference scenario for each variation of temperature profiles

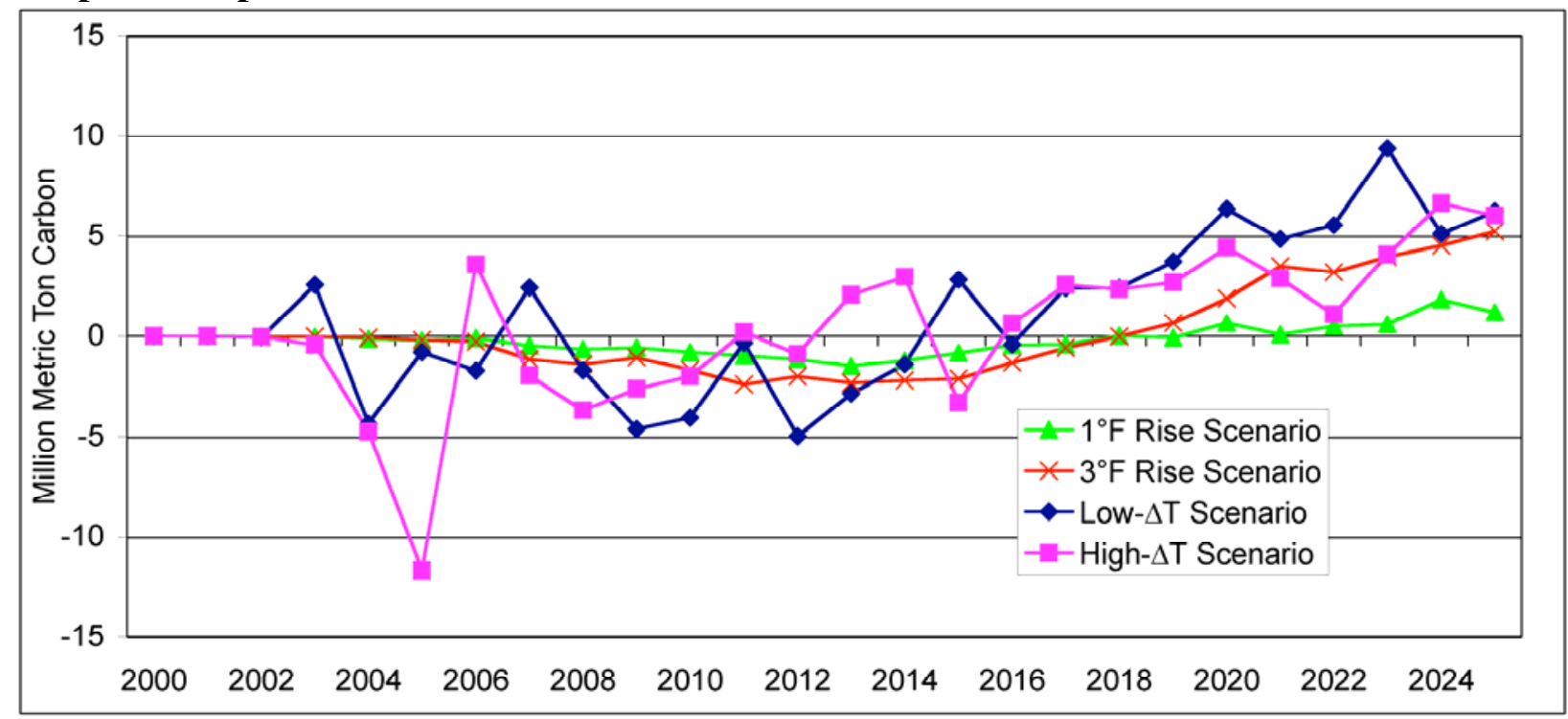

The analytical tools used in this work could be improved to better refine the insights provided. A suite of climate simulations should be examined. The direct conversion of temperatures to degree-days using NCDC's weighting factors directly could improve accuracy. The Rosenthal 
paper suggests that the reference point for degree-days should be different than $65^{\circ} \mathrm{F}$. The effect of these changes on energy use sensitivity to temperature may be enlightening. The underlying NEMS model is continually being updated with better algorithms and input data, so the modifications we used here should be transferred to the most recent version for better analysis of variations in degree-days. There exists a variant of NEMS that extends to 2050. Applying the degree-day modifications to it could show results when temperature changes and consequent energy changes may be more dramatic. Finally, DD-NEMS is a very complex model. The addition of temperature-induced variations in energy demands may not be accurately accounted for in other algorithms and modules of the program. This should be further examined for accuracy and robustness.

The results we have gathered so far in our analysis show that the interaction of climate and energy modeling can provide valuable insights to researchers and policymakers and should be continued. 


\section{References}

Barnett, Tim P., David W. Pierce, Reiner Schnur: 2001: Detection of Anthropogenic Climate Change in the World's Oceans Science, 292 (5515):270-274.

EIA (Energy Information Administration) 1997, State Energy Data Report 1997, Consumption Estimates, DOE/EIA-0214(97), U.S. Department of Energy, Washington, DC, November.

EIA 1999, A Look at Residential Energy Consumption in 1997, DOE/EIA-632(97), U.S. Department of Energy, Washington, DC, November.

<http://www.eia.doe.gov/emeu/recs/contents.html>

EIA 2002, A Look at Commercial Buildings in 1999: Characteristics, Energy Consumption, and Energy Expenditures, DOE/EIA-625(9), U.S. Department of Energy, Washington, DC, November, <http://www.eia.doe.gov/emeu/cbecs/>

EIA (Energy Information Administration) 2003a, Annual Energy Outlook 2003: With Projections to 2025, DOE/EIA-0383 (2003) Washington, DC: U.S. Department of Energy, January. < http://www.eia.doe.gov/oiaf/aeo/index.html>

EIA 2003b, The National Energy Modeling System: An Overview 2003, DOE/EIA-0581 (2003) Washington, DC: U.S. Department of Energy, March.

<www.eia.doe.gov/oiaf/aeo/overview/index.html>

EIA 2003c, Assumptions for the Annual Energy Outlook 2003, DOE/EIA-0554 (2003)

Washington, DC: U.S. Department of Energy, January.

< http://www.eia.doe.gov/oiaf/archive/aeo03/assumption/index.html>

Hadley, Stanton W., David J. Erickson III, Jose Luis Hernandez, and Starley Thompson (2004). "Future U.S. Energy Use for 2000-2025 as Computed with Temperatures from a Global Climate Prediction Model and Energy Demand Mode." Proceedings of the 24th Annual North American Conference of the USAEE, United States Association for Energy Economics, Cleveland, OH.

Meehl, G.A., P. Gent, J.M. Arblaster, B. Otto-Bliesner, E. Brady, and A. Craig, 2000: Factors that affect amplitude of El Nino in global coupled climate models. Climate Dynamics, Volume 17 Issue 7 (2001) pp 515-526.

National Assessment Synthesis Team (NAST) 2000, Climate Change Impacts on the United States, U.S. Global Change Research Program, Cambridge University Press.

<http://www.gcrio.org/NationalAssessment/index.html>

NCDC 2003a, U.S. Climate Normals, National Oceanic and Atmospheric Administration website $<$ http://www5.ncdc.noaa.gov/cgi-

bin/climatenormals/climatenormals.pl?directive=prod_select2\&prodtype=HCS5\&subrnum=> 
NCDC 2003b, Heating and Cooling Degree Day Data, National Oceanic and Atmospheric Administration website, < http://www.ncdc.noaa.gov/oa/documentlibrary/hcs/hcs.html>

Rosenthal, Donald H, Howard K. Gruenspecht and Emily Moran 1995 "Effects of global warming on energy use for space heating and cooling in the United States", Energy Journal, Volume 16 Issue 2, pp. 77-96.

Washington, W.M., J.W. Weatherly, G.A. Meehl, A.J. Semtner, Jr., T.W. Bettge, A.P. Craig, W.G. Strand, Jr., J.M. Arblaster, V.B. Wayland, R. James, Y. Zhang, 2000: Parallel climate model (PCM) control and transient simulations, Climate Dynamics, Volume 16 Issue 10/11 (2000) pp 755-774 